\title{
Experimental study on milling force in processing Ti6Al4V thin-walled part
}

\author{
Zeng Hui Jiang ${ }^{1, a}$, Min Fei Jia ${ }^{2, b}$ and Peng He Liu ${ }^{3, c}$ \\ 1,2 School of Mechanical Engineering, Shenyang Ligong University, Shenyang 110159, China \\ ${ }^{3}$ School of Mechanical Engineering, Dalian Ligong University, Dalian 116024, China \\ aizh1022@163.com, ${ }^{\mathrm{b} J M F 0803 @ 163 . c o m},{ }^{9}$ Iphdllg@163.com
}

\begin{abstract}
Keywords: Ti6Al4V thin-walled part . Milling force . Orthogonal experiment . Machining parameters . Significance
\end{abstract}

Abstract. Ti6Al4V thin-walled part have been widely used in the field of aerospace, shipbuilding with the excellent properties of light weight, high strength, good corrosion resistance. But the thin-walled part has lower rigidity; the cutting force and vibration generated in cutting process can deform the work piece easily and make surface quality worse. In order to perfect machining quality and improve processing efficiency of Ti6Al4V thin-walled part, the paper study the significance of cutting speed, feed per tooth, axial cutting depth and radial cutting depth on the milling force, and do a further research on experience formula of milling force. The results show that: the cutting force FX, FY and FZ increase with the increasing of feed per tooth, axial cutting depth and radial cutting depth. The cutting force FX and FY increase firstly then decrease with the increase of cutting speed. The cutting force FZ changes volatility with the increase of cutting speed. The radical cutting depth has the largest significance on cutting force. The error of milling force formula established by experimental date is about $20 \%$. So the formula can calculate the milling force well.

\section{Introduction}

Ti6AL4V thin-walled parts can meet the requirements of higher strength, small size, and has a good overall performance, and more good toughness, plasticity and high temperature deformation properties, can be better hot-pressing process. But its complex structure, poor processing technology and large material removal of the processing deformation and surface quality difficult to control, so that the workpiece processing accuracy can not be guaranteed.The milling force is the most important factor for machining deformation and easily cause vibration, which seriously restricts the processing quality and processing efficiency of the parts [1-4]. Many scholars carried on a large amount research aiming at cutting force, vibration and varies physical phenomenon in machining process of milling Ti6Al4V thin-wall parts. In order to enhance surface integrity, tool life, stability and productivity effectively, confirming processing parameters by optimizing cutting conditions is very important. Mecheri Kious [5] detected the tool wear on-line with an automatic monitoring system and analyzed the influence of the clamp holes and the machining cycle to the quality of tool. And the use of several signal measurements to improve the on-line tool breakage detection and grinding of the coating tool monitoring. The results of the study show that they are significantly increased with side wear. You can set threshold levels to estimate tool life. Moaz H. Ali [6] suggested a model for predicting surface roughness with feed cutting force by finite element modeling. It is found that there is a good relationship between the cutting force and the roughness trend at different cutting rates. Thus, infinite element modeling can be used to predict the value of the feed cutting force to control the surface roughness rather than experiment. The finite element can reduce processing time and manufacturing costs. Halil Çalışkan[7] investigated the effect of coating on surface integrity, chip formation of the Ti6Al4V work piece. The results of the study show that the coating is proven to be effective in chip formation and surface finish. The aCN / TiAlN coating is a good candidate for surface milling of Ti6A14V alloys due to its excellent properties in adhesion, abrasion resistance, surface finish and chip formation. Lionel Arnaud [8] evaluated the modeling of machining vibrations of aluminium thin-walled work pieces by numerical simulation method. This method is novel for thin-walled 
processing, since prior simulation simulations were performed without actual processing. The comparison between the experiment and the simulation is very good in the relationship between the cutting force prediction and the shape. The results show that the simulation can predict the actual chatter frequency, which is very helpful for improving thin-wall milling. Armando Ítalo Sette Antonialli [9] studied the influence of tool entering angle and vibration on the stability of the titanium alloy milling process and on tool life. The research found that lower entering angle could make tool life longer,and Lower vibration will prevent damage to the cutting edge caused by fatigue, which can solve the problem of tool wear reduction. M. A. DAVIES [10] used a mechanics-based model with impact nonlinearities to explain test results and suggested that impact dynamics are likely to dominate vibrations in milling thin-walled structure. All the analysis of work piece vibration, tool wear and machining precision is all based on the cutting force. So the establishment of cutting force model is the most intuitive method for studying them. Some research point that forces level tends to decrease with increasing cutting speed, the cutting forces are proportionally affected by the feed velocity, the down-cutting mode is more favorable for small path intervals and depths of cut [11]. Tunç Lütfi Taner [12] presented a generalized cutting force model for multi-axis milling, and the model goes well about the comparison of the simulation and experiment result. In the proposed model, the cutting tool housing can be defined as the speed of the multi-section curve or defined using a seven-parameter cutter. A new rapid method based on projection geometry is used to calculate the joint between the cutting tool housing and the workpiece, and the prediction is verified and discussed by cutting experiments using multi-axis machining conditions of various cutting tool geometries. M. Fontaine [13] built milling force model according to thermo mechanical behaviors of the work piece material and the tool-chip interface friction characteristic. Szymon Wojciechowski [14] proposed an accurate cutting force model with new method of specific force coefficients calibration.Studies have shown that in terms of quantification and qualitative, both the cutting force and the vibration are strongly influenced by the tilt angle of the surface. The highest cutting force and displacement amplitude are generated during upward tilt, with the highest study surface tilt angle. T. Radhakrishnan [15] studied a empirical relationship between cutting force and the cutting parameters by using both multiple regression and neural network modeling processes. Generally, the method of establishing cutting force should be simply and effectively for reducing the relevant effort and cost. W.-S.Yun, D.-W.Cho[16] suggested an improved method for determining constant cutting force coefficients by the combination of experimentally determined cutting force with simulation cutting force model and geometric uncut chip thickness model. In addition, this study presents a method of estimating the jitter-related parameters and the jitter offset and its position angle using only one cut force measurement. For a wide range of cutting conditions, this method of estimating the strength coefficient of the 3D end milling has been experimentally verified, and the cutting force is significantly better than any other method. H. Perez [17] proposed a new cutting force model based on the average chip thickness of the engaged cutting flute in peripheral milling. It can estimate the cutting force under variable machining conditions.

The paper study the influence of cutting speed, the feed per tooth, the axial depth of cut and the radical depth of cut on milling force by orthogonal experiment in the process of machining Ti6Al4V thin-wall parts, discuss the significant influence of the above four factors on the milling force and choose the exponential formula as a model for researching cutting force. In section 2 make a detail introduction on exponential formula. In section 3 shows the test equipment and process. In section 4 discuss the test results. In section 5 the cutting force model is fitted through experimental date and the error is discussed further.

\section{Exponential formula of milling force}

The milling force model is established on the complicate relationship between cutting force and machining parameters. Just as the following:

$$
F=C_{F} \cdot V^{\mathrm{b}_{1}} \cdot f_{z}^{b_{2}} \cdot a_{p}^{b_{3}} \cdot a_{e}^{b_{4}}
$$


CF --- Coefficient decided by processing material and cutting conditions; b1, b2, b3, b4 ----- The index of the four parameters。

The formula can be simplified a linear equation:

$$
\begin{aligned}
& y=b 0+b 1 x 1+b 2 \times 2+b 3 \times 3+b 4 x 4 \\
& y=\lg F, \quad b 0=\operatorname{lgCF}, \quad x 1=\operatorname{lgv}, \quad x 2=\operatorname{lgfz}, \quad x 3=\lg a, \quad x 4=\operatorname{lgae}
\end{aligned}
$$

There are four independent variables which respectively is cutting speed, feed per tooth, the axial cutting depth, the radical cutting depth. The y stands for cutting force. So we can get the coefficient of formula by designing specific experiment and determine the milling force formula finally.

\section{Experiments}

Experimental materials

The part material is Ti6Al4V, a typical $\alpha+\beta$ titanium alloy. Table 1 presents its chemical composition. The shape of the thin-wall parts has been simplified for acquiring accuracy date. Work piece size is that: the length is $\mathrm{L}=80 \mathrm{~mm}$; the height is $\mathrm{H}=80 \mathrm{~mm}$; the thickness is $\mathrm{T}=5 \mathrm{~mm}$.

Table 1 The chemical constituents of TC4 titanium alloy

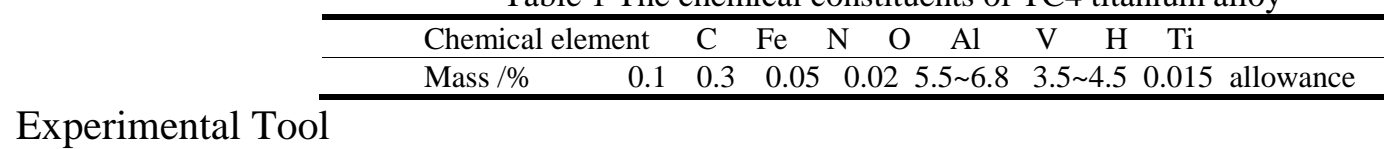

The tool is integral cemented carbide end mill produced by SANDVIK Coromant. The diameter is $\mathrm{Dc}=16 \mathrm{~mm}$ and helical angle is $\beta=-50^{\circ}$.The maximum axial cutting depth is ap $=36 \mathrm{~mm}$.

Experimental setup

The machining equipment used in milling experiment is EUMA ME650 vertical machining center. Its specifications are given in Table 2.

The acquisition device of cutting force is $9123 \mathrm{C}$ rotation dynamometer. The signal simplification device is 5223B multi-channel charge amplifier. The date acquisition card is 2855A5.

Table 2 Vertical machining center

\begin{tabular}{llll}
\hline Spindle speed & X stroke & Y stroke & Z stroke \\
$80 \sim 8000 \mathrm{r} / \mathrm{min}$ & $650 \mathrm{~mm}$ & $450 \mathrm{~mm}$ & $460 \mathrm{~mm}$ \\
\hline
\end{tabular}

Experimental procedure

This paper regard cutting speed, feed per tooth, axial cutting depth and radical cutting depth as the four main factors expressed in A, B, C, D respectively. The four factors and four levels orthogonal experiment is designed by the four main factors as the table 3 shows.

\begin{tabular}{|c|c|c|c|c|c|}
\hline Level & Level value & $\begin{array}{c}\text { A (cutting speed) } v \\
(\mathrm{~m} / \mathrm{min})\end{array}$ & $\begin{array}{c}\text { B (feed per tooth) } \\
f_{\mathrm{z}}(\mathrm{mm} / \mathrm{z})\end{array}$ & $\begin{array}{l}\text { C(axial cutting } \\
\text { depth) } a_{\mathrm{p}}(\mathrm{mm})\end{array}$ & $\begin{array}{l}\mathrm{D} \text { (radical cutting } \\
\text { depth ) } a_{\mathrm{e}}(\mathrm{mm})\end{array}$ \\
\hline Level 1 & 1 & 50.24 & 0.06 & 3 & 0.5 \\
\hline Level 2 & 2 & 75.36 & 0.08 & 4 & 0.6 \\
\hline Level 3 & 3 & 100.48 & 0.10 & 5 & 0.7 \\
\hline Level 4 & 4 & 125.60 & 0.12 & 6 & 0.8 \\
\hline
\end{tabular}

Table 3 The L16 $\left(4^{4}\right)$ table of orthogonal experiment level

The picture 1 shows the date collection place of cutting force experiment. The working principle of whole system is that dynamometer acquire analog signal of the cutting force in the machining process, 
then input date acquire card which convert the analog signal to digital signal after the charge amplified. Finally the software of DynoWare in the computer will deal with the cutting force signal.
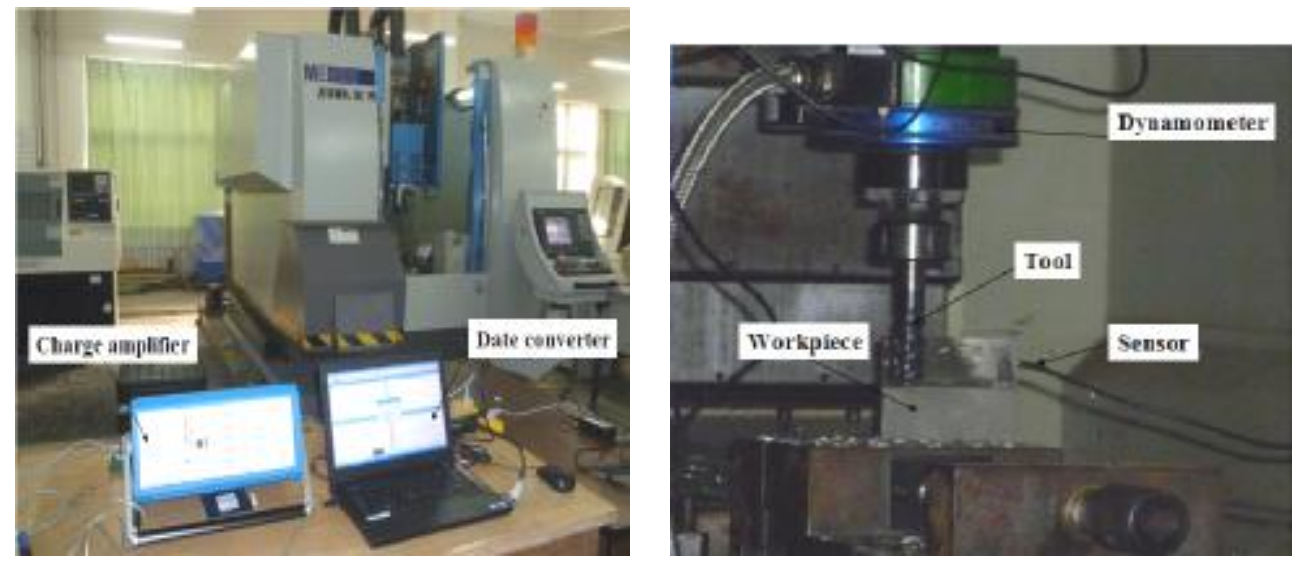

Fig. 1 Cutting force measuring system

\section{Result and discussion}

Signal processing of cutting force

The L16 (44) orthogonal table is established based on orthogonal test level table 2 . The date of the 16 groups is used for orthogonal cutting experiment. In this paper one of the group with the cutting parameters of $v=50.24 \mathrm{~m} / \mathrm{min}, \mathrm{fz}=0.06 \mathrm{~mm} / \mathrm{z}, \mathrm{ap}=4 \mathrm{~mm}$ and $\mathrm{ae}=0.6 \mathrm{~mm}$ is taken for example for analyzing cutting force signal of FX, FY and FZ. The result is shown in the picture 2.

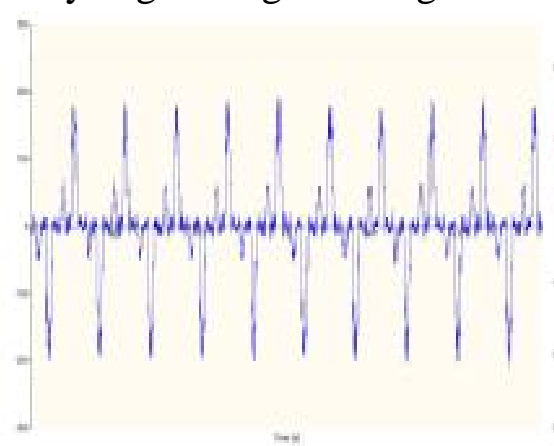

(a) $F_{\mathrm{x}}$ signal chart

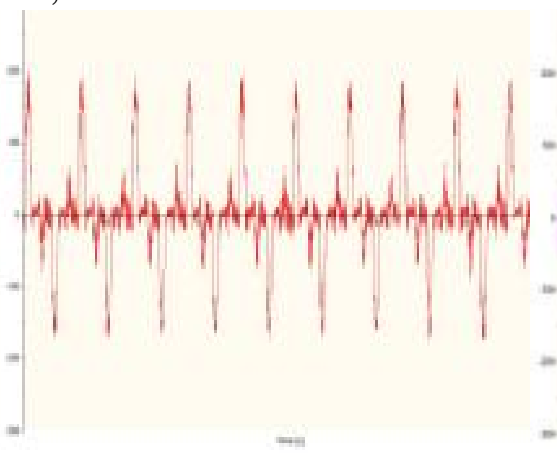

(b) $F_{\mathrm{y}}$ signal chart

Fig. 2.The signal chart of cutting force

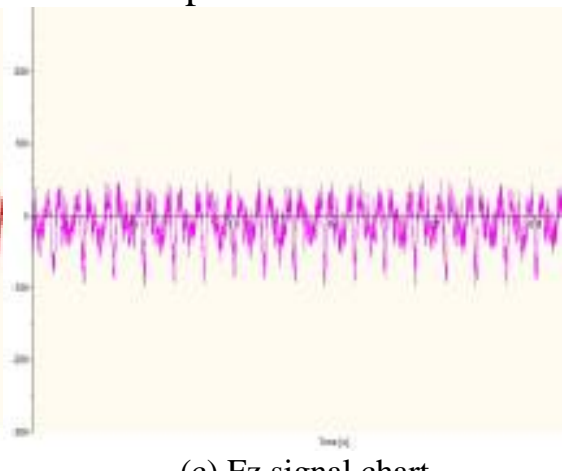

(c) Fz signal chart

In order to get the measured value of FX ,FZ, FY cutting force, the peak value of three directions should be intercepted respectively and get the average value. Just as the following table 4 present. 
Table 4 The L16 $\left(4^{4}\right)$ orthogonal experiment results of milling force

\begin{tabular}{cccccccc}
\hline $\begin{array}{c}\text { Experiment serial } \\
\text { number }\end{array}$ & $\begin{array}{c}\text { Cutting } \\
\text { speed } \\
(\mathrm{m} / \mathrm{min})\end{array}$ & $\begin{array}{c}\text { Feed per } \\
\text { tooth } \\
(\mathrm{mm} / \mathrm{z})\end{array}$ & $\begin{array}{c}\text { Axial cutting } \\
\text { depth } \\
(\mathrm{mm})\end{array}$ & $\begin{array}{c}\text { Radical } \\
\text { cutting depth } \\
(\mathrm{mm})\end{array}$ & $\begin{array}{c}F_{x} \text { measured } \\
\text { value } \\
(\mathrm{N})\end{array}$ & $\begin{array}{c}F_{y} \text { measured } \\
\text { value } \\
(\mathrm{N})\end{array}$ & $\begin{array}{c}F_{x} \text { measured } \\
\text { value }\end{array}$ \\
\hline 1 & 50.24 & 0.06 & 3 & 0.5 & 120.41 & 112.56 & 40.56 \\
2 & 50.24 & 0.08 & 4 & 0.6 & 167.34 & 161.05 & 77.35 \\
3 & 50.24 & 0.10 & 5 & 0.7 & 209.83 & 207.18 & 109.75 \\
4 & 50.24 & 0.12 & 6 & 0.8 & 258.34 & 262.56 & 131.33 \\
5 & 75.36 & 0.06 & 4 & 0.7 & 168.74 & 164.33 & 51.29 \\
6 & 75.36 & 0.08 & 3 & 0.8 & 203.81 & 196.94 & 76.76 \\
7 & 75.36 & 0.10 & 6 & 0.5 & 177.65 & 175.01 & 68.17 \\
8 & 75.36 & 0.12 & 5 & 0.6 & 215.62 & 210.30 & 74.07 \\
9 & 100.48 & 0.06 & 5 & 0.8 & 186.75 & 182.16 & 123.84 \\
10 & 100.48 & 0.08 & 6 & 0.7 & 193.89 & 189.33 & 116.67 \\
11 & 100.48 & 0.10 & 3 & 0.6 & 158.36 & 169.24 & 55.47 \\
12 & 100.48 & 0.12 & 4 & 0.5 & 165.32 & 167.68 & 81.36 \\
13 & 125.60 & 0.06 & 6 & 0.6 & 148.93 & 148.56 & 66.84 \\
14 & 125.60 & 0.08 & 5 & 0.5 & 151.73 & 154.38 & 71.32 \\
15 & 125.60 & 0.10 & 4 & 0.8 & 207.44 & 213.75 & 108.97 \\
16 & 125.60 & 0.12 & 3 & 0.7 & 181.03 & 187.52 & 61.38 \\
\hline
\end{tabular}

The influence of machining parameters on milling force

The influence of different machining parameters on milling force can be got through the range analysis of table 3. As the following fig. 3 - fig. 6 show.

Cutting speed changes as shown in the fig. 3 have not a significance impact on machining force FX and FY but for FZ. The deformation resistance on the shear zone increase with the increase of strain hardeningof material. Interrupted cutting also causes the increase of impact force and dynamic machining force. In addition, the high temperature can make the processing materials soften and decrease the machining force. When the increase of dynamic machining force and the strain hardening at the dominate place, the machining force will increase with the increase of cutting speed and otherwise the opposite. The processed material soften will at the dominate place when the flank wear of tool get a certain degree. Then the machining force will decrease with the increase of cutting speed.

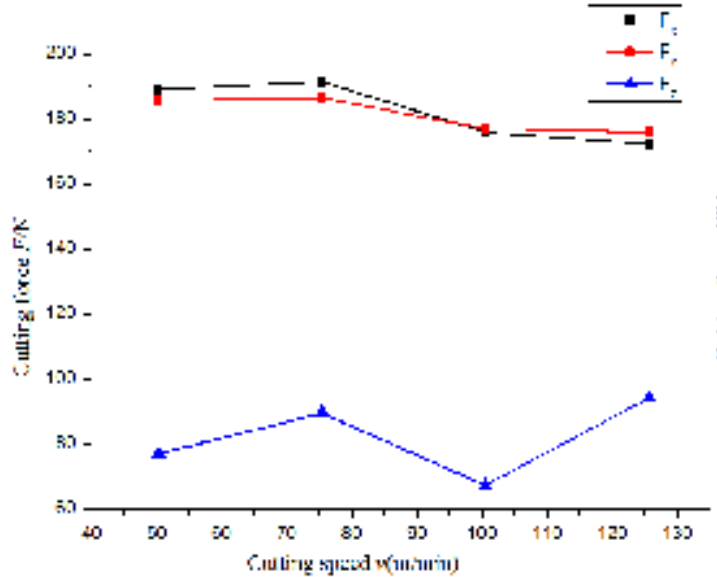

Fig. 3 Effect on cutting force of cutting speed

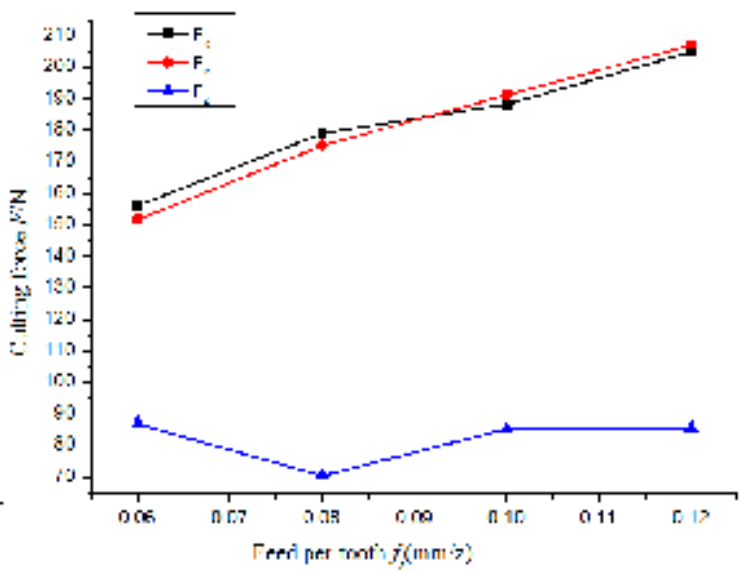

Fig.4 Effect on cutting force of feed per tooth

The fig. 4 shows the change law of FX, FY and FZ cutting force with the feed per tooth. As the picture shows, the FX and FY cutting force have a obvious increasing trend in the range of feed per tooth from $0.06 \mathrm{~mm} / \mathrm{z}$ to $0.12 \mathrm{~mm} / \mathrm{z}$, and relatively larger than FZ. The increase trend of FZ machining force becomes slowly with the increase of the feed per tooth. This indicates that the change of feed per tooth have significant effect on FX and FY machining force but not for FZ machining force. 

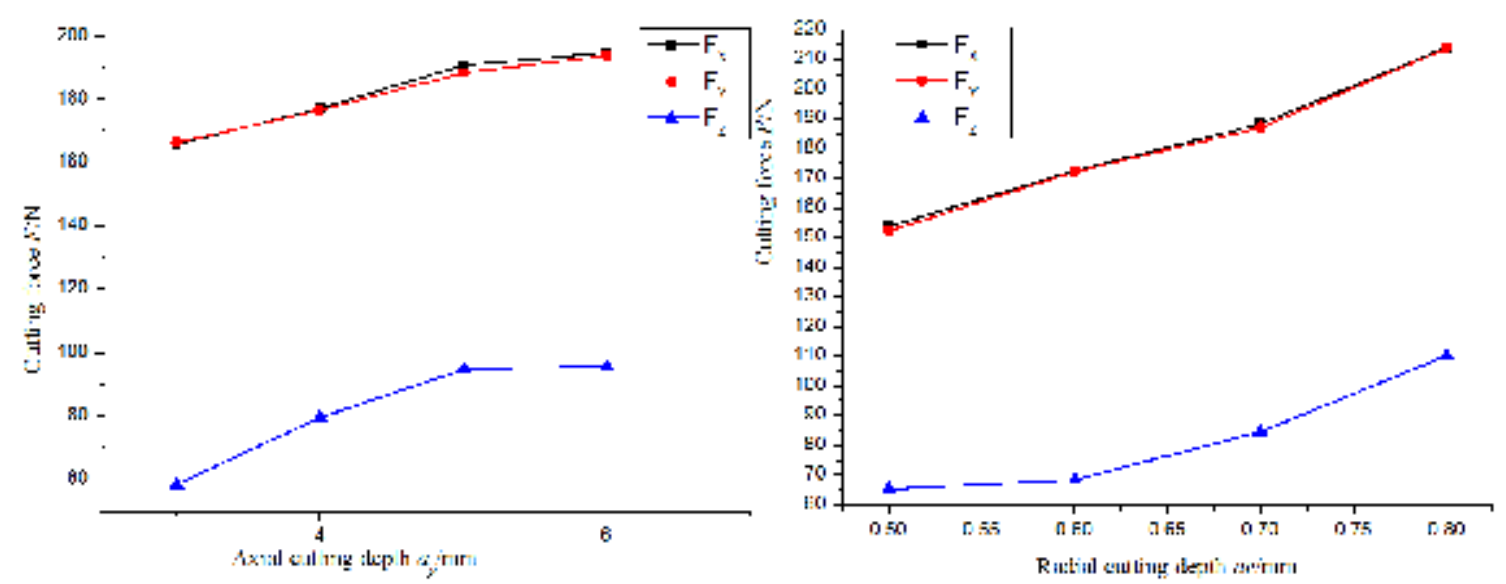

Fig.5 Effect on cutting force of axial depth of cut Fig.6 Effect on cutting force of radial depth of cut

The fig. 5 and fig. 6 have similarities trend with the fig.4. The reason is that the increase of any parameters will make cross-sectional area of cutting layer increase and the impact force will be larger and the machining force will be increase finally.

Variance analysis

Variance analysis is a very practical statistical identifying method. It can be used for testing the significance of related factors combining $\mathrm{F}$ value testing and it has a high guiding significance for improving processing efficiency. The table 5 shows the judging standard of $F$ value testing. We take the variance analysis of FX for an example; the calculation process as the following.

Table 5 The judging standard of $F$ value testing

\begin{tabular}{llc}
\hline Judging criteria & Influence degree & Representation \\
\hline $\mathrm{F}>\mathrm{F} 0.01(\mathrm{f} 1, \mathrm{f} 2)$ & High significance & $* *$ \\
$\mathrm{~F} 0.05(\mathrm{f} 1, \mathrm{f} 2)<\mathrm{F}<\mathrm{F} 0.01(\mathrm{f} 1, \mathrm{f} 2)$ & significance & $*$ \\
$\mathrm{~F}<\mathrm{F} 0.05(\mathrm{f} 1, \mathrm{f} 2)$ & No significance & - \\
\hline
\end{tabular}

(1) Calculating sum of squares deviations :

$$
\begin{aligned}
T & =\sum_{i=1}^{16} F_{x i}=120.41+167.34+\cdots+181.03=2915.19 \\
Q & =\sum_{i=1}^{16} F_{x i}{ }^{2}=120.41^{2}+167.34^{2}+\cdots+181.03^{2} \\
& =547215.4777
\end{aligned}
$$$$
P=\frac{T^{2}}{n}=\frac{2915.19^{2}}{16}=531145.796
$$

$S S_{T}=Q-P=16069.682$

$$
\begin{aligned}
S S_{A} & =\frac{r}{n}\left(K_{11}^{2}+K_{12}{ }^{2}+K_{13}^{2}+K_{14}{ }^{2}\right)-P \\
& =1069.739
\end{aligned}
$$

In the same way: $\mathrm{SSB}=4981.958, \mathrm{SSC}=2095.814, \mathrm{SSD}=7821.892$

Sum of squares deviations of error:

$$
S S_{e}=S S_{T}-\left(S S_{A}+S S_{B}+S S_{C}+S S_{D}\right)=100.280
$$

(2) Calculating degree of freedom: 


$$
\begin{aligned}
& d f_{T}=n-1=16-1=15 \\
& d f_{A}=d f_{B}=d f_{C}=d f_{D}=r-1=4-1=3 \\
& d f_{e}=d f_{T}-\left(d f_{A}+d f_{B}+d f_{C}+d f_{D}\right)=3
\end{aligned}
$$

(3) Calculating average variance:

$$
M S_{A}=\frac{S S_{A}}{d f_{A}}=356.58
$$

In the same way: $\mathrm{MSB}=1660.653, \mathrm{MSC}=698.605, \mathrm{MSD}=2607.297, \mathrm{MSe}=33.427$. Because the value of MSA、MSB, MSC, MSD all higher than MSe, so we can ignore them.

(4) Calculating the F value:

$$
F_{A}=\frac{M S_{A}}{M S_{e}}=10.668
$$

In the same way: $\mathrm{FB}=49.681, \mathrm{FC}=20.900, \mathrm{FD}=78.001$.

(5) F test:

The critical value of F0.05 $(3,3)=9.28$, F0.01 $(3,3)=29.46$ can be getting from the F value distribute table. The variance analysis table of Fx can be get according to the above calculate result as the table 6 shows.

The variance analysis of FY and FZ is shown in Table 7 and Table 8using the same method.

Table 6 The variance analysis table of $F_{\mathrm{x}}$

\begin{tabular}{ccccccc}
\hline $\begin{array}{l}\text { Variance } \\
\text { resource }\end{array}$ & $\begin{array}{c}\text { sum of squares } \\
\text { deviations }\end{array}$ & $\begin{array}{c}\text { Freedom } \\
\text { degree }\end{array}$ & $\begin{array}{c}\text { Average } \\
\text { variance }\end{array}$ & $\begin{array}{c}\mathrm{F} \\
\text { value }\end{array}$ & $\begin{array}{c}\text { Significant test } \\
\text { value }\end{array}$ & significance \\
\hline A & 1069.739 & 3 & 356.580 & 10.668 & 0.041 & $*$ \\
B & 4981.958 & 3 & 1660.653 & 49.681 & 0.005 & $* *$ \\
C & 2095.814 & 3 & 698.605 & 20.900 & 0.016 & $*$ \\
D & 7821.892 & 3 & 2607.297 & 78.001 & 0.002 & $* *$ \\
Error e & 100.280 & 3 & 33.427 & - & - & \\
\hline
\end{tabular}

Table 7 The variance analysis table of $F_{\mathrm{y}}$

\begin{tabular}{ccccccc}
\hline $\begin{array}{c}\text { Variance } \\
\text { resource }\end{array}$ & $\begin{array}{c}\text { sum of squares } \\
\text { deviations }\end{array}$ & $\begin{array}{c}\text { Freedom } \\
\text { degree }\end{array}$ & $\begin{array}{c}\text { Average } \\
\text { variance }\end{array}$ & \multicolumn{2}{c}{$\begin{array}{c}\text { F value } \\
\text { significance }\end{array}$} & $\begin{array}{c}\text { Significant test } \\
\text { value }\end{array}$ \\
\hline A & 377.061 & 3 & 125.687 & 1.447 & 0.384 \\
B & 6639.368 & 3 & 2213.123 & 25.475 & 0.012 \\
C & 1792.003 & 3 & 597.334 & 6.876 & 0.074 \\
D & 8036.573 & 3 & 2678.858 & 30.836 & 0.009 \\
Error e & 260.624 & 3 & 86.875 & - & - \\
\hline
\end{tabular}

Table 8 The variance analysis table of $F_{\mathrm{z}}$

\begin{tabular}{ccccccc}
\hline $\begin{array}{l}\text { Variance } \\
\text { resource }\end{array}$ & $\begin{array}{c}\text { sum of } \\
\text { squares }\end{array}$ & $\begin{array}{c}\text { Freedom } \\
\text { degree }\end{array}$ & $\begin{array}{c}\text { Average } \\
\text { variance }\end{array}$ & F value & $\begin{array}{c}\text { Significant test } \\
\text { value }\end{array}$ & significance \\
\hline A & 1775.668 & 3 & 591.889 & 13.003 & 0.032 & $*$ \\
B & 718.928 & 3 & 239.643 & 5.265 & 0.103 & - \\
C & 3627.055 & 3 & 1209.018 & 26.561 & 0.012 & $*$ \\
D & 5061.602 & 3 & 1687.201 & 37.066 & 0.007 & $*$ \\
Error e & 136.556 & 3 & 45.519 & - & - & \\
\hline
\end{tabular}

The three tables show that the radial cutting depth has the most significance impact on FX, FY and FZ in the process of milling titanium thin-wall parts. The cutting speed and axial cutting depth have no 
significance on FY, and the feed per tooth has no significance on FZ, so we can increase those no significance parameters value before it reaches the F0.05 for improving the machining efficiency.

\section{The establishment of milling force model}

According to formula 1 MATLAB software give a multiple linear regression using the date of table 2 and estimate the regression coefficient of b0, b1, b2, b3, b4 selecting least square method. Finally getting the linear regression model between, FX, FY, FZ and cutting speed, depth peer tooth, axial cutting depth, radial cutting depth as the following:

$$
\begin{array}{llll}
F_{x}=641.80 v^{-0.0796} f_{z}^{0.3772} a_{p}^{0.2411} a_{e}^{0.6967} & R^{2}=0.9514 & \mathrm{~F}=53.7969 \\
F_{y}=636.91 v^{-0.0261} f_{z}^{0.4466} a_{p}^{0.2294} a_{e}^{0.7113} & R^{2}=0.9662 & \mathrm{~F}=78.5649 \\
F_{z}=71.408 v^{0.0440} f_{z}^{0.2382} a_{p}^{0.7132} a_{e}^{1.2680} & R^{2}=0.7448 & \mathrm{~F}=8.0265
\end{array}
$$

The closer R2 value nearly to 1 , the better multiple linear regression equation is fitting. The value of FX, FY and FZ are all greater than 5.67 because F0.01 (p,n-p-1)=F0.01(4,11)=5.67. This explains that the regression equation is very significant and has a high degree fitting with practical condition.

With certain value of $\mathrm{v}=100.48 \mathrm{~m} / \mathrm{min}, \mathrm{fz}=0.08 \mathrm{~mm} / \mathrm{z}, \mathrm{ae}=0.7 \mathrm{~mm}, \mathrm{ap}=10 \mathrm{~mm}$ test the fitting formula. The result can be seen from table 9 .

Table 9 Milling force error testing

\begin{tabular}{lllll}
\hline milling force & cutting step & theoretical value $(\mathrm{N})$ & trial value(N) & error $(\%)$ \\
$\mathrm{F}_{\mathrm{x}}$ & 1 & 233.05 & 187.51 & 24.29 \\
$\mathrm{Fy}$ & 1 & 240.52 & 219.10 & 9.78 \\
$\mathrm{Fz}$ & 1 & 157.52 & 119.01 & 32.36 \\
$\mathrm{Fx}$ & 2 & 233.05 & 207.22 & 12.47 \\
$\mathrm{Fy}$ & 2 & 240.52 & 230.38 & 4.4 \\
$\mathrm{Fz}$ & 2 & 157.52 & 135.27 & 16.45 \\
$\mathrm{Fx}$ & 3 & 233.05 & 202.6 & 15.03 \\
$\mathrm{Fy}$ & 3 & 240.52 & 239.57 & 0.4 \\
$\mathrm{Fz}$ & 3 & 157.52 & 146.85 & 7.27 \\
\hline
\end{tabular}

The table 9 shows that the error of milling force equation is about $20 \%$, so the equation can figure out the milling force to a certain degree. There is a bigger error of Fz in the cutting step 1. This is because vibration easily happen when milling thin-wall part, so the trial value of Fz include other force which make the cutting force value inaccuracy.

\section{Conclusions}

The relationship of milling force with cutting speed, feed per tooth, axial cutting depth, and radial cutting depth in the processing of dry milling Ti6Al4V thin-wall parts is studied by orthogonal experiment. The influence of cutting parameters on milling force and significant level can be acquired by variance analysis on the result. Besides, the milling force empirical formula is obtained by fitting the orthogonal experimental data. The conclusions getting from the paper as the following:

(1) The cutting force of $F_{X}, F_{Y}$ and $F_{Z}$ increase with the feed per tooth, axial cutting depth and radial cutting force increasing. The cutting force of $F_{X}$ and $F_{Y}$ increase firstly and then decrease with the increase of cutting speed. The cutting force of $F_{Z}$ has a volatility change with the increase of cutting speed.

(2) The radical cutting depth is the largest significance on cutting force and the cutting speed and axial cutting depth have no significance on $F_{Y}$. We can improve machining 
efficiency by increaseing cutting speed and axial cutting depth.

(3) The milling force empirical formula has a good fitting with the actual condition.

\section{Acknowledgements}

This work was financially supported by the National S \& T Major Project (2012ZX04003-061).

\section{References}

[1] Pan Ling Huang, Jian Feng Li, Jie Su (2014) Study on performance in dry milling aeronautical titanium alloy thin-wall components with two types of tools. Journal of Cleaner Production, 67:258-264.

[2] Liu Gang (2009) Study on deformation of titanium thin-walled part in milling process. Journal of Materials Processing Technology, 209:2788-2793.

[3] Vincent Thevenot, Lionel Arnaud, Gilles Dessein, Gilles Cazenave-Larroche (2006) Integration of dynamic behaviour variations in the stability lobes method:3D lobes construction and application to thin-walled structure milling. The International Journal of Advanced Manufacturing Technology, 27: 638-644.

[4]Ján Ravinger(2003) Vibration of an imperfect thin-walled panel. Part 1: Theory and illustrative examples. Thin-Walled Structures, 19:1-22.

[5] Mecheri Kious ,M. Boudraa ,A. Ouahabi ,R. Serra (2008) Influence of machining cycle of horizontal milling on the quality of cutting force measurement for the cutting tool wear monitoring. Production Engineering, 2:443-449.

[6] Moaz H. Alia, Basim A. Khidhirb, M.N.M. Ansaria, Bashir Mohamedc (2013)

FEM to predict the effect of feed rate on surface roughness with cutting force during face milling of titanium alloy. HBRC Journal,9: 263 - 269.

[7] Halil Çalı ş kan, Meriç Küçükköse (2015) The effect of aCN/TiAlN coating on tool wear, cutting force, surface finish and chip morphology in face milling of Ti6Al4V superalloy. International Journal of Refractory Metals and Hard Materials, 50:304-312.

[8] Lionel Arnaud, Oscar Gonzalo, Sébastien Seguy, Haritz Jauregi, Grégoire Peigné (2011) Simulation of low rigidity part machining applied to thin-walled structures. The International Journal of Advanced Manufacturing Technology, 54:479-488.

[9] Armando Ítalo Sette Antoniallia, Anselmo Eduardo Dinizb, Robson Pederivab (2010) Vibration analysis of cutting force in titanium alloy milling. International Journal of Machine Tools and Manufacture. 50:65-74.

[10] M. A. DAVIES, B. BALACHANDRAN (2000) Impact Dynamics in Milling of Thin-Walled Structures. Nonlinear Dynamics, 22: 375-392.

[11] M. Fontaine, A. Moufki, A. Devillez, D. Dudzinski(2007) Modeling of cutting forces in ball-end milling with tool-surface inclination: Part II. Influence of cutting conditions, run-out, ploughing and inclination angle. Journal of Materials Processing Technology, 189: 85-96.

[12] Tunç Lütfi Taner, Özkirimli Ömer, Budak Erhan (2015) Generalized cutting force model in multi-axis milling using a new engagement boundary determination approach. The International Journal of Advanced Manufacturing Technology, 77:341-355 
[13] M. Fontaine, A. Moufki, A. Devillez, D. Dudzinski (2007) Modeling of cutting forces in ball-end milling with tool-surface inclination Part I: Predictive force model and experimental validation. Journal of Materials Processing Technology, 189: 73-84.

[14] Szymon Wojciechowski (2014) The estimation of cutting forces and specific force coefficients during finishing ball end milling of inclined surfaces .International Journal of Machine Tools and Manufacture 89:110-123.

[15] T. Radhakrishnan,Uday Nandan (2005) Milling force prediction using regression and neural networks. Journal of Intelligent Manufacturing, 16(1)93-102.

[16] W.-S. Yun and D.-W. Cho (2000) An Improved Method for the Determination of 3D Cutting Force Coefficients and Runout Parameters in End Milling. The International Journal of Advanced Manufacturing Technology 16:851-858.

[17] H. Perez, E. Diez, J. J. Marquez, A. Vizan (2013) An enhanced method for cutting force estimation in peripheral milling. The International Journal of Advanced Manufacturing Technology, 69:1731-1741. 


\title{
Experimental Research on geogrids Creep property of at different low temperatures
}

\author{
Lianzhong Yin \\ No.212, West Zhongyuan Road, Zhengzhou City, Henan Province, P.R.China ,Henan Electric \\ Power Survey and Design Institute \\ yinlianzhong-heny@powerchina.cn.
}

Keywords: geogrids, creep property, creep test

Abstract: Creep property is the key factor for effecting geogrid-reinforced earth retaining structures under a long-term behavior. Contrast test is adopted for creep property of geogrids under different temperature in the indoor test. The result indicates as follows: creep property of plastic geogrids is totally different with different temperature. So temperature has a great influence on creep property of geogrids. The lower the temperature is, the smaller the creep is.

\section{Introduction}

As the development of geotechnical composite material, geotechnical reinforced fabrics is extensive used in the permanent project. Under different temperature and load, geotextile produces different properties which can weaken the function of reinforcement and damage the buildings ${ }^{[1]}$. So it is very important to study on creep property of reinforced earth retaining structure. With economic development, many project will be founded in the lower temperature area.In order to display the function of geotextile under the lower temperature, the creep property should be studied.

Now many domestic and overseas scholars ${ }^{[2-10]}$ have been studied on creep test of geogrids. TGDG25 one-way tensile geogrids is used is indoor test. The temperature is among $-20^{\circ} \mathrm{C},-10^{\circ} \mathrm{C}$ and $0^{\circ} \mathrm{C}$.In need of contrast, the test is also done at $10^{\circ} \mathrm{C}$ and $20^{\circ} \mathrm{C}$. In order to guide engineering practice, this text makes an analysis of the result of creep property at a low temperature.

\section{Creep test mechanics and physical quantity}

Creep deformation is that material is deforming as time is increasing, but the load dose not change. Geotechnical composite material is made of polymeric material. Creep property of geogrids has influenced on geogrid-reinforced earth retaining structures in a long-term behavior. Creep deformation of reinforced earth retaining structure and stress relaxation can lead to the change of internal stress; This will cause an accident such as losing the whole stability, excessive deformation and so on. It is the key for tensile strength whether it acts long-term or not. When geotechnical composite material is used to strengthen, creep property is very important.

Relating to plastic geogrids' physical quantity of creep test :

(1) creep strain Test sample of creep strain is the ratio of extension to initial length under the longterm static loads.

$$
\varepsilon=\frac{\mathrm{L}-\mathrm{L}_{0}}{\mathrm{~L}_{0}}
$$

In equation: $\varepsilon$ - creep strain; $\quad l-$ ength of sample at any time, $\mathrm{mm} ; \quad \mathrm{L}_{0}-$ initial length of sample, $\mathrm{mm}$.

(2) Creep stress: Creep stress is the ratio of external force to sectional area.

$$
\sigma=\frac{F}{S}
$$

In equation: $\delta$ - creep stress, Pa; F- external force of sample, $\mathrm{N} ; \mathrm{S}$ - sectional area of sample, $\mathrm{m}$. 
(3) Intensity In common, dimension of intensity is the same as stress, but intensity of geogrids is force at the unit-width. In national standards, intensity is defined as stretcher yield force each meter; we consider this method .Load intensity is expressed by equation (3) under feeding and data processing.

$$
\begin{gathered}
\mathrm{L}=\frac{\mathrm{F}}{\mathrm{W}} \quad \text { (3) } \\
\quad \text { In equation: } \\
\mathrm{L}-\text { Load intensity, } \mathrm{N} / \mathrm{m} ; \mathrm{F}-\text { Load of sample, } \mathrm{N} ; \mathrm{W}-\text { Length of sample, } \mathrm{m} \text {; }
\end{gathered}
$$

\section{Test apparatus, material and processing}

Test apparatus Temperature control lab: internal dimensions: $6.40 \mathrm{~m} \times 5.10 \mathrm{~m} \times 2.95 \mathrm{~m}$, it is composted of cold compress machine with large power and computer temperature control machines. The range of temperature is $+20^{\circ} \mathrm{C} \sim-35^{\circ} \mathrm{C}$, control accuracy is $\pm 0.5^{\circ} \mathrm{C}$. Tensile-testing machine must be put in the indoor.

Creep deformation tester: it is made by us. Creep test is running in adjustable temperature and humidity. Creep test machine of geogrids sample is shown in the graph1. According to graph 1, top and bottom side clamps of measurement system are individually fixed on top and bottom boundary at initial length $\mathrm{L}_{0}$. These are tow micrometer gauges fixed on the top clamp, which read the change of measurement range. Freezing loop temperature is controlled in $-20{ }^{\circ} \mathrm{C} \sim+20{ }^{\circ} \mathrm{C}$.

Test material In this test, material adopt TGDG25 one-way tensile geogrids; Qualification of TGDG25 geogrids is showed in the table 1.considering about special mesh structure of geogrids and avoiding size effect, samples use five longitudinal ribs. The length of sample is $100 \mathrm{~cm}$. Effective length of geogrids is the distance between top and bottom clamping fixture. Extension of creep deformation is displacement value between two parallel cross-bars which belongs to measuring displacement table.

Table 1 qualification of TGDG25 geogrids

\begin{tabular}{c|c|c|c|c|c}
\hline Project & $\begin{array}{c}\text { A unit of } \\
\text { mass } \\
(\mathrm{g} / \mathrm{m} 2)\end{array}$ & $\begin{array}{c}\text { Tensile yield } \\
\text { force at each } \\
\text { meter } \\
\geq(\mathrm{kN} / \mathrm{m})\end{array}$ & $\begin{array}{c}\text { Yield } \\
\text { extensibility } \leq \\
(\%)\end{array}$ & $\begin{array}{c}\text { Tensileforce of } \\
2 \% \\
\text { extensibility } \geq(\mathrm{kN} \\
/ \mathrm{m})\end{array}$ & $\begin{array}{c}\text { Tensileorce of 5\% } \\
\text { extensibility } \geq(\mathrm{kN} / \mathrm{m})\end{array}$ \\
\hline TGDG25 & $370 \pm 50$ & 25 & 10 & 77 & 14 \\
\hline
\end{tabular}

Test process $20 \%, 40 \%$ and $60 \%$ of bearing capacity is taken for creep test under horizontal effect. Fetching $0 \mathrm{~min} 、 1 \mathrm{~min} 、 5 \mathrm{~min} 、 8 \mathrm{~min} 、 12 \mathrm{~min} 、 30 \mathrm{~min} 、 1 \mathrm{~h} 、 2 \mathrm{~h} 、 4 \mathrm{~h} 、 8 \mathrm{~h} 、 12 \mathrm{~h} 、 24$ $h 、 3 d, 7 d, 14 d, 21 d, 42 d \ldots .$. These times are deformation of authorized points of geogrids.

Experimental error: deformation measurement adopts micrometer. Its accuracy is $\mathrm{mm}$ and error is $0.1 \%$. Outside the two gauge length, distance is $25 \mathrm{~mm}$ between lines of gauge length and clamping fixture, this can avoid the influence on deformation which is caused by retaining.

Method of retained sample: the top clamping fixture has two armor plates as well as the bottom one. It has nonskid canal inside. Use bolts to screw up and fix sample. It is required that the retaining is equalization. It can not appear destruction, which is caused by non-uniform loads after feeding.

Test environment: Test temperature is at $-20^{\circ} \mathrm{C},-10^{\circ} \mathrm{C}, 0^{\circ} \mathrm{C}, 10^{\circ} \mathrm{C}$, and $20^{\circ} \mathrm{C}$.Put three samples on the creep tester, control temperature in the indoor, protect from direct sunlight and ultraviolet ray.

Loads: Use weights as loads. Hang the loads on lever system as tensile load. Horizontal load is $5 \%, 10 \%, 20 \%$ of rupture strength. 
Strain measurement: Time spacing increases gradually. Sensing time is $0 \mathrm{~min}, 1 \mathrm{~min}, 8 \mathrm{~min}$, $12 \mathrm{~min}, 30 \mathrm{~min}, 1 \mathrm{~h}, 2 \mathrm{~h}, 4 \mathrm{~h}, 8 \mathrm{~h}, 12 \mathrm{~h}$, and $24 \mathrm{~h}$. After that, the sensing time is $24 \mathrm{~h}$ at intervals until 1000h.Strain is extension of sample gauge length divided by initial length.

\section{Test result and analysis}

When recording of test data and drawing of curve are beginning, it measures a time interval at 1 min, $6 \mathrm{~min}, 12 \mathrm{~min}, 30 \mathrm{~min}, 1 \mathrm{~h}, 2 \mathrm{~h}, 3 \mathrm{~h}, 5 \mathrm{~h}, 7 \mathrm{~h}$ and $10 \mathrm{~h}$. After that it measures every 24 hours. The record is originating from the time of left and right instrument. Average deformation of left and right rib is used as the whole deformation at every time. Total time of this record is $1600 \mathrm{~h}$. According to base data, graph of time-strain is shown as follows:

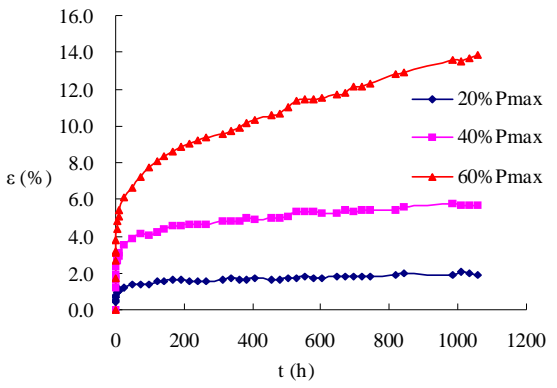

Fig.1-1 Curve of stress and strain at $20^{\circ} \mathrm{C}$

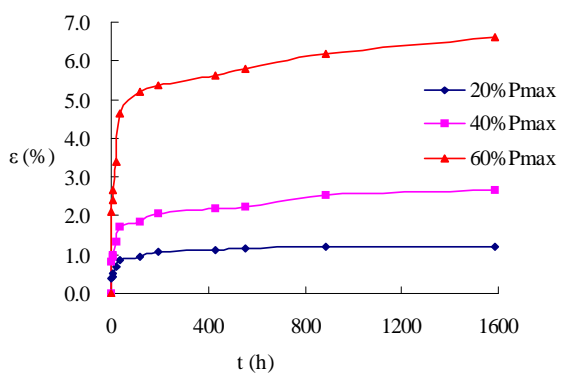

Fig. 1-2 Curve of stress and strain at $10{ }^{\circ} \mathrm{C}$

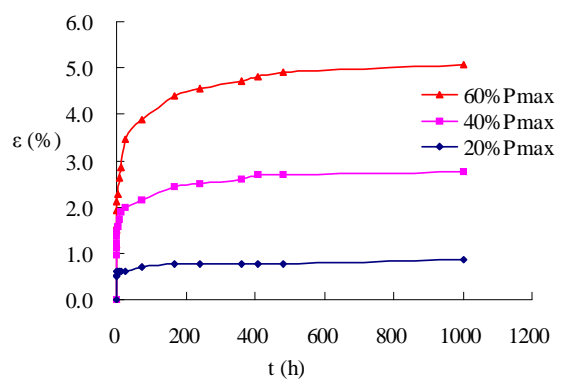

Fig. 1-3 Curve of stress and strain at $0{ }^{\circ} \mathrm{C}$

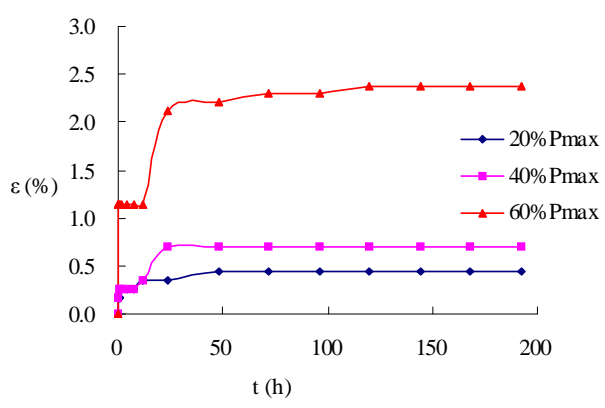

Fig. 1-4 Curve of stress and strain at $-10{ }^{\circ} \mathrm{C}$

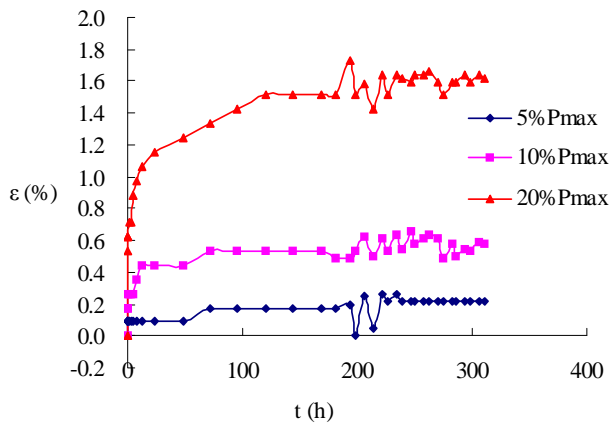

Fig.1-5 Curve of stress and strain at $-20{ }^{\circ} \mathrm{C}$

The main feature of creep behavior is gained through that analyzing creep data. According to graph 2, the more the loads are, the lager the strain in the same time. When the load is than less or equal to $40 \%$, the curve of strain is becoming flat after $400 \mathrm{~h}$ at $20^{\circ} \mathrm{C}$. This is shown that change of creep becomes less and less. When the load is more than $40 \%$, the curve becomes comparatively cliffy. The strain has exceeded 5\% within short time. According to the conclusion, geogrids should not be used when the loads are higher than $40 \%$.

At the beginning, the curve of strain rises steeply under $-20^{\circ} \mathrm{C}$. However, the curve tends to be constant after only 100 hours and extensibility dose not reach $2.5 \%$. It shows that environment temperature has a notable impact on creep property. 


\section{Conclusions}

The main results and conclusion are as follows:

(1)Creep deformation of plastic geogrids at a low temperature is totally different from the condition at a normal temperature. Under $-20^{\circ} \mathrm{C}$, the curve of strain rises steeply tends to be constant after only 100 hours and extensibility dose not reach $2.5 \%$. When extensibility is approaching $14 \%$ after 1000 hours at $20{ }^{\circ} \mathrm{C}$, the deformation is still not becoming stability under 60 percent of max-pressure. So the temperature has a great influence on creep property of geogrids. The lower the temperature is, the smaller the creep is. The design value of plastic geogrids should be properly decreased at a low temperature.

(2) The extensibility of One-way strengthened plastic geogrids with time is recorded through the test. According to the curve of strain-time, when load is small, the creep is flat. If the load is large, the creep of strain is large and develops quickly.

(3) From the test result, the deformation of geogrid is large under various stresses at the beginning. But it becomes flat and even nearly stops after a time. So we can draw the conclusion that Once reinforced earth retaining structure is built after a period, it is safe if the deformation within the permission.

\section{References}

[1] Sam Deok Cho, Kwang Wu Lee, Daniele A. Cazzuffi and Han Yong Jeon(2006). Evaluation of combination effects of installation damage and creep behavior on long-term design strength of geogrids. Polymer Testing:819-828

[2] Yi-Chong Guo, Chun-Ling Xin, Ming-Shi Song and Ya-Dong He(2005) Study on short- and long-term creep behavior of plastics geogrid Polymer Testing: 793-798

[3] RLUN Maotian,XIAO Cheng and zhi ANG Qing(2005). Experimental study on creep propeties and viscoelasticity constitutive relationship for geogrids.Rock and Soil Mechanics:187-192

[4] Luan Maotian, Xiao Chengzhi andYang Qing (2006). An experimental study on the creep behavior of geogrids under long-term external loading. China Civil Engineering Journal:87-91

[5] Guo Yichong, Xin Chunling Chen Qiang and Jia Zongjie(2005). Prediction of long-term creep behaviors of plastics geogrid.Engineering Plastics Application:53-56

[6]Han-Yong Jeon, Seong Hun Kim, Won Seok Lyoo, Chungsik Yoo and George R. Koerner(2006). Evaluation of the long-term performance of geosynthetic reinforcements from their reduction factors. Polymer Testing: 289-295 


\title{
Design of Fuzzy Self - tuning PID Controller for Master-Slave Manipulator Force Sensing System
}

\author{
Xiao-Dong LIANG ${ }^{1, a}$, Zhong-Kai Chen ${ }^{1, b}$, Ye Sun ${ }^{1, c}$, Hong-Bo LIAO $^{1, d}$ \\ ${ }^{1}$ Northwest Institute of Nuclear Technology, xi'an 710024,China \\ axiaodoudong@126.com, ${ }^{\mathrm{b}}$ chzhk@mail.ustc.edu.cn, ${ }^{\mathrm{c}}$ 123sunye@163.com, \\ 13975890826@163.com
}

\begin{abstract}
Keywords: master-slave manipulator force sensing system; fuzzy self-tuning PID controller; matlab/simulink

Abstract. For the problems about large disturbances, delays and nonlinear of master-slave manipulator force sensing system, the paper designed a fuzzy self-tuning PID controller and carried out simulation analysis by matlab/simulink. The result showed that the designed controller can effectively improve the dynamic and steady state of the force control system.
\end{abstract}

\section{Introduction}

In the industrial process, PID control is widely used because of its simple principle, convenient operation and strong robustness. But as for some systems with large disturbances, delays and nonlinear, it is difficult to establish the precise mathematical model by traditional PID controller. Parameter tuning is difficult and the best parameters are easy to drift, so the controller parameters must be adjusted off-line or on-line to obtain reasonable values. Fuzzy self-tuning PID control combines the traditional PID control and fuzzy control and the advantages of both sides. It can adjust the parameters of PID online and in real time, which is a kind of advanced control system at present $^{[2,3,4]}$.

Aiming at the problems about large disturbances, delays and nonlinear of master-slave manipulator force sensing system, we designed a fuzzy self-tuning PID controller and carded out simulation analysis by matlab/simulink. The result showed that the designed controller can effectively improve the dynamic and steady state of the force control system.

\section{Introduction of the master-slave manipulator force sensing system}

The master-slave manipulator consists of three parts: the master hand, the slave hand and the control system, as shown in figure 1 . The operator passes the joint movement command through the master hand to control the movement of the slave hand. When the slave hand reaches the working position for clamping operation, the clamping handle of the master hand output signal to control the slave hand gripper closed, thus the clamping and handling operation is done. The control system is mainly responsible for collecting position information and force information, driving the power components, coordinating and controlling the master and slave manipulator.
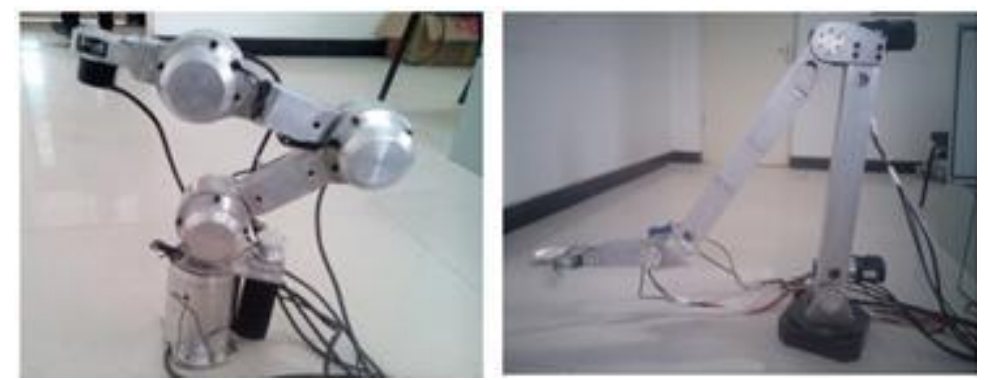

Fig. 1 Physical Drawing of The Master-Slave Manipulator 
Master-slave manipulator force control system can sense the clamping force change of the salve hand in real time and realize the feedback of the clamping force, so that the operator has a sense of clamping force. It is mainly composed of force sensor, motion controller, computer, master hand force feedback handle, wire rope, motor controller and motor. The system control block diagram is shown in figure 2.

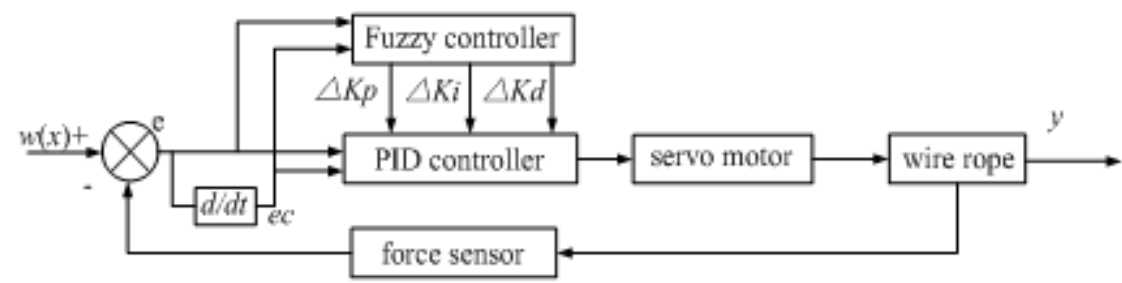

Fig. 2 Block Diagram of Force Control System

It can be seen from figure 2 , in the force control system the control quantity is the tension at the end of the wire rope, and the force servo control is achieved through that the AC servo motor drives rope wheel to pull the wire rope. The tension of the wire rope is the key quantity and terminal quantity of the control, and the pulling force is detected by the tension and pressure sensor.

\section{Controller Design}

Fuzzy control is a kind of control method using fuzzy set theory. The rationality and advantages of fuzzy control are as follows: Fuzzy control proposes a new mechanism of control law based on rule language, and provides a new theory and method for system and device with uncertain model parameters, time variability and non-linearity.

Determination of membership function about input and output quantity. According to the PID parameter self-tuning principle, the fuzzy self-tuning PID controller is designed as a double-input three-output type, the input quantity is the force control signal deviation $e$ and the deviation change rate $e c$, where the deviation $e$ is equal to the difference between the two measured wire rope tension signals, and the deviation change rate $e c=e k$-ek-1, the output is $\Delta K_{p}, \Delta K_{i}, \Delta K_{d}$.

Force deviation $e:[-6,6]$; deviation change rate $e c$ : [- 6,6]; output $\Delta K_{p}:[-0.6,0.6]$

Output $\Delta K_{i}:[-6,6]$; output $\Delta K_{d}:[-0.06,0.06]$

The fuzzy subset in the fuzzy controller is expressed by \{negative big, negative middle, negative small, zero, positive small, positive middle, positive big\}:

$E=\{\mathrm{NB}, \mathrm{NM}, \mathrm{NS}, \mathrm{Z} 0$, PS, PM, PB $\}$

$E C=\{\mathrm{NB}, \mathrm{NM}, \mathrm{NS}, \mathrm{Z} 0, \mathrm{PS}, \mathrm{PM}, \mathrm{PB}\}$

$\Delta K_{p}, \Delta K_{i}, \Delta K_{d}=\{\mathrm{NB}, \mathrm{NM}, \mathrm{NS}, \mathrm{Z} 0, \mathrm{PS}, \mathrm{PM}, \mathrm{PB}\}$ 

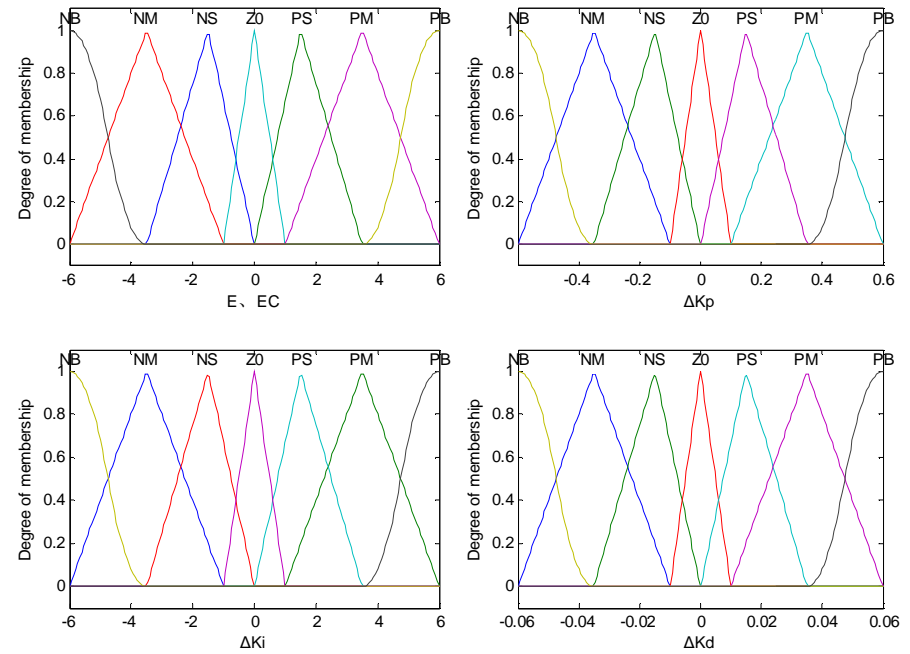

Fig. 3 Membership Function Curve of $E, E C, \Delta K_{p}, \Delta K_{d}, \Delta K_{i}$

Determine the fuzzy control rules. The control rules are in the form of if $e$ and $e c$ then $\Delta K$. According to expert rules and computer simulation debugging, the final determined fuzzy control rules of $\Delta \mathrm{Kp}, \Delta \mathrm{Ki}$ and $\Delta \mathrm{Kd}$ are shown in table $1 \sim 3$.

Table 1 Fuzzy Control Rules Table of Scale Coefficient

\begin{tabular}{|c|l|l|l|l|l|l|l|l|}
\hline \multicolumn{2}{|c|}{$\Delta \boldsymbol{K}_{\boldsymbol{p}}$} & \multicolumn{7}{|c|}{$\boldsymbol{E}$} \\
\cline { 2 - 9 } & $\boldsymbol{N B}$ & $\boldsymbol{N M}$ & $\boldsymbol{N S}$ & $\boldsymbol{Z O}$ & $\boldsymbol{P S}$ & $\boldsymbol{P M}$ & $\boldsymbol{P B}$ \\
\hline \multirow{7}{*}{$\boldsymbol{E} \boldsymbol{C}$} & $\boldsymbol{N B}$ & PB & PB & PM & PM & PM & PM & PB \\
\cline { 2 - 9 } & $\boldsymbol{N M}$ & PB & PB & PM & PM & PM & PM & PB \\
\cline { 2 - 9 } & $\boldsymbol{N} \boldsymbol{S}$ & PM & PM & PM & Z0 & PM & PS & PM \\
\cline { 2 - 9 } & $\boldsymbol{Z O}$ & PM & PS & PS & PS & PM & PB & PB \\
\cline { 2 - 9 } & $\boldsymbol{P S}$ & PS & PS & Z0 & NS & NS & NM & NM \\
\cline { 2 - 9 } & $\boldsymbol{P M}$ & Z0 & Z0 & NS & NM & NM & NM & NB \\
\cline { 2 - 10 } & $\boldsymbol{P B}$ & Z0 & NS & NS & NM & NM & NB & NB \\
\hline
\end{tabular}

Table 2 Fuzzy Control Rules Table of Integral Coefficient

\begin{tabular}{|c|c|c|c|c|c|c|c|c|}
\hline \multirow{2}{*}{\multicolumn{2}{|c|}{$\Delta \boldsymbol{K}_{i}$}} & \multicolumn{7}{|c|}{$E$} \\
\hline & & $N B$ & $N M$ & $N S$ & $Z 0$ & $P S$ & $P M$ & $P B$ \\
\hline \multirow{7}{*}{$\boldsymbol{E}$} & $N B$ & NB & NB & NB & NB & PM & PB & PB \\
\hline & $N M$ & NB & NB & NM & NB & $\mathrm{PM}$ & PB & PB \\
\hline & $N S$ & NM & NM & NM & NB & PS & PM & PM \\
\hline & $Z 0$ & NB & $\mathrm{NS}$ & $\mathrm{NM}$ & $\mathrm{NM}$ & PS & PS & PB \\
\hline & $P S$ & $\mathrm{NS}$ & $\mathrm{NS}$ & NM & NM & PS & PM & PM \\
\hline & $P M$ & $\mathrm{ZO}$ & $\mathrm{ZO}$ & PS & NM & PM & PB & PB \\
\hline & $P B$ & $\mathrm{ZO}$ & $\mathrm{ZO}$ & PS & $\mathrm{NM}$ & PB & PB & PB \\
\hline
\end{tabular}

Table 3 Fuzzy Control Rules Table of Differential Coefficient

\begin{tabular}{|c|c|l|l|l|l|l|l|l|}
\hline \multicolumn{2}{|c|}{$\Delta \boldsymbol{K}_{\boldsymbol{d}}$} & \multicolumn{7}{|c|}{$\boldsymbol{E}$} \\
\cline { 2 - 9 } & $\boldsymbol{N B}$ & $\boldsymbol{N M}$ & $\boldsymbol{N S}$ & $\boldsymbol{Z O}$ & $\boldsymbol{P S}$ & $\boldsymbol{P M}$ & $\boldsymbol{P B}$ \\
\hline \multirow{4}{*}{$\boldsymbol{E} \boldsymbol{C}$} & $\boldsymbol{N B}$ & PB & PM & PB & PB & PB & Z0 & NB \\
\cline { 2 - 9 } & $\boldsymbol{N M}$ & PM & PS & PM & PM & PM & NS & NB \\
\cline { 2 - 9 } & $\boldsymbol{N S}$ & PS & Z0 & PS & PS & PS & NM & NB \\
\cline { 2 - 9 } & $\boldsymbol{Z O}$ & NB & NM & NM & NS & Z0 & PS & PM \\
\cline { 2 - 9 } & $\boldsymbol{P S}$ & NB & NB & PS & PS & PS & Z0 & PS \\
\hline
\end{tabular}




\begin{tabular}{|l|l|l|l|l|l|l|l|l|}
\hline & $\boldsymbol{P M}$ & NB & NS & PM & PM & PM & PS & PM \\
\cline { 2 - 8 } & $\boldsymbol{P B}$ & NB & Z0 & PB & PB & PB & PM & PB \\
\hline
\end{tabular}

In the process of online self-tuning of PID parameters, the tension and pressure sensor can measure the actual tension pressure in real time, compare it with the set input value (expected value) to obtain the force deviation $e$, calculate $e k$-ek-1 and obtain the deviation rate $e c$. Set $e$ and $e c$ as the input of fuzzy controller, $K_{p}, K_{i}, K_{d}$ can be obtained through fuzzification, fuzzy rule selection and fuzzy clustering algorithm. According to the formula (1), we can obtain $K_{p}, K_{i}, K_{d}$, and the self-tuning PID control parameters, and then apply them to the control.

$$
\mu=\frac{\sum \mu\left(u_{i}\right) \cdot u_{i}}{\sum \mu\left(u_{i}\right)_{i}}
$$

Where: $u_{i}$ and $\mu\left(u_{i}\right)$ respectively represent the centroid and membership values of the symmetric membership functions.

Run Matlab, open the FIS editor, create * fis file, and select the control type as Mamdani type. "AND" operation adopts "prod", "OR" operation adopts "probor", fuzzy implication adopts "prod", fuzzy rule synthesis adopts "probor", defuzzification method adopts gravity method. The fuzzy controller and the membership function interface are shown in figure 4 and figure 5.

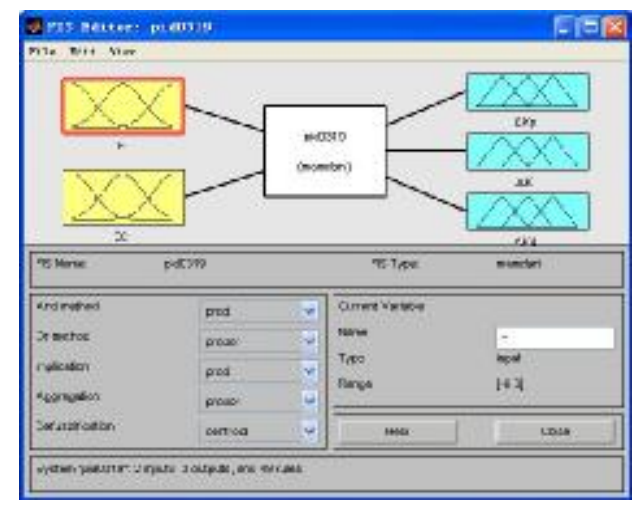

Fig. 4 Interface of Fuzzy Controller

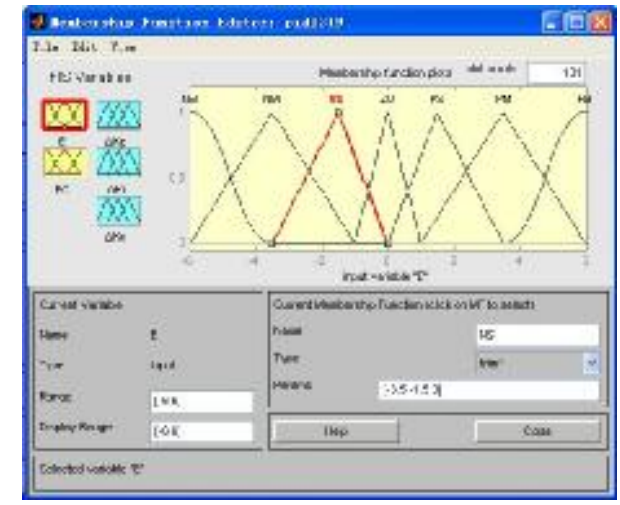

Fig. 5 Interface of Membership Function

Using the fuzzy rule editor, according to the control rules in table $1 \sim 3$ to edit, and get the rules of the input and output variables as shown in figure 6 , the curve surface of fuzzy relation is shown in figure 7 9.

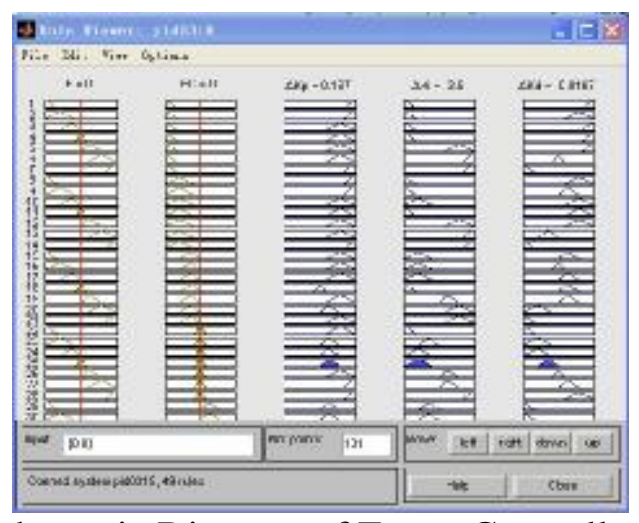

Fig. 6 Schematic Diagram of Fuzzy Controller Rule

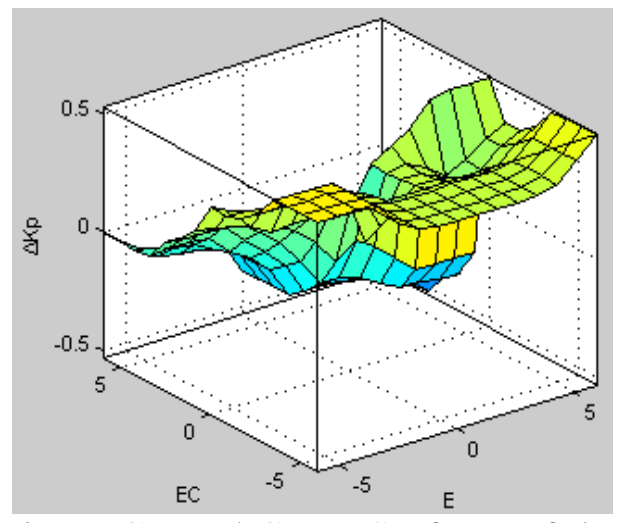

Fig. 7 Control Curve Surfaces of $\Delta K_{p}$ 


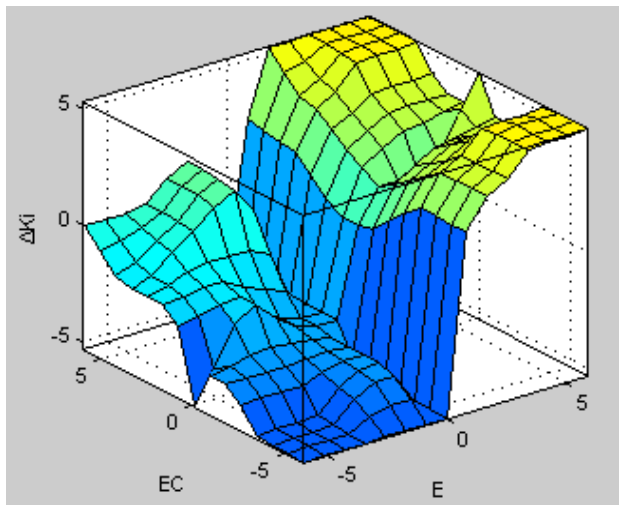

Fig. 8 Control Curve Surfaces of $\Delta \mathrm{Ki}$

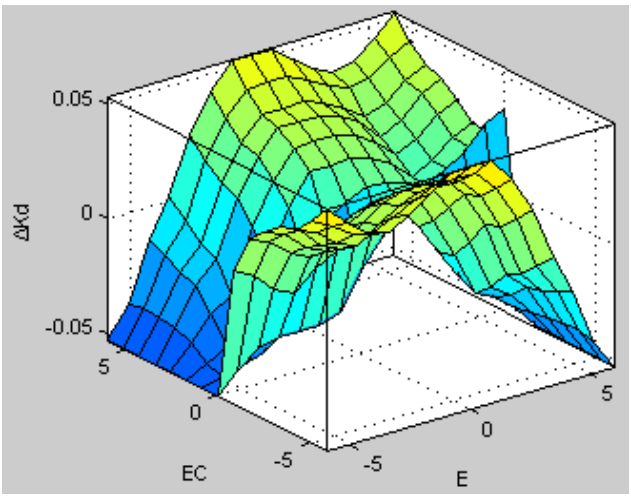

Fig. 9 Control Curve Surfaces of $\Delta K_{d}$

\section{Simulation analysis}

Construct the simulation model of the force system in the matlab / simulink, and drag the fuzzy logic controller module to the simulation model of the force system, and then carry out the simulation analysis, as shown in figure 10. Add the output $\Delta K_{p}, \Delta K_{i}, \Delta K_{d}$ of the fuzzy logic inference device which are weighted by the influence factor to the initial value of the PID parameter as the output of the PID controller. The parameters adjusted by the critical proportion method of the PID parameters are: $K_{p}=3.71, K_{i}=240, K_{d}=0.001$, the scale factors $\Delta p, \Delta i$ and $\Delta d$ are taken as 1 .

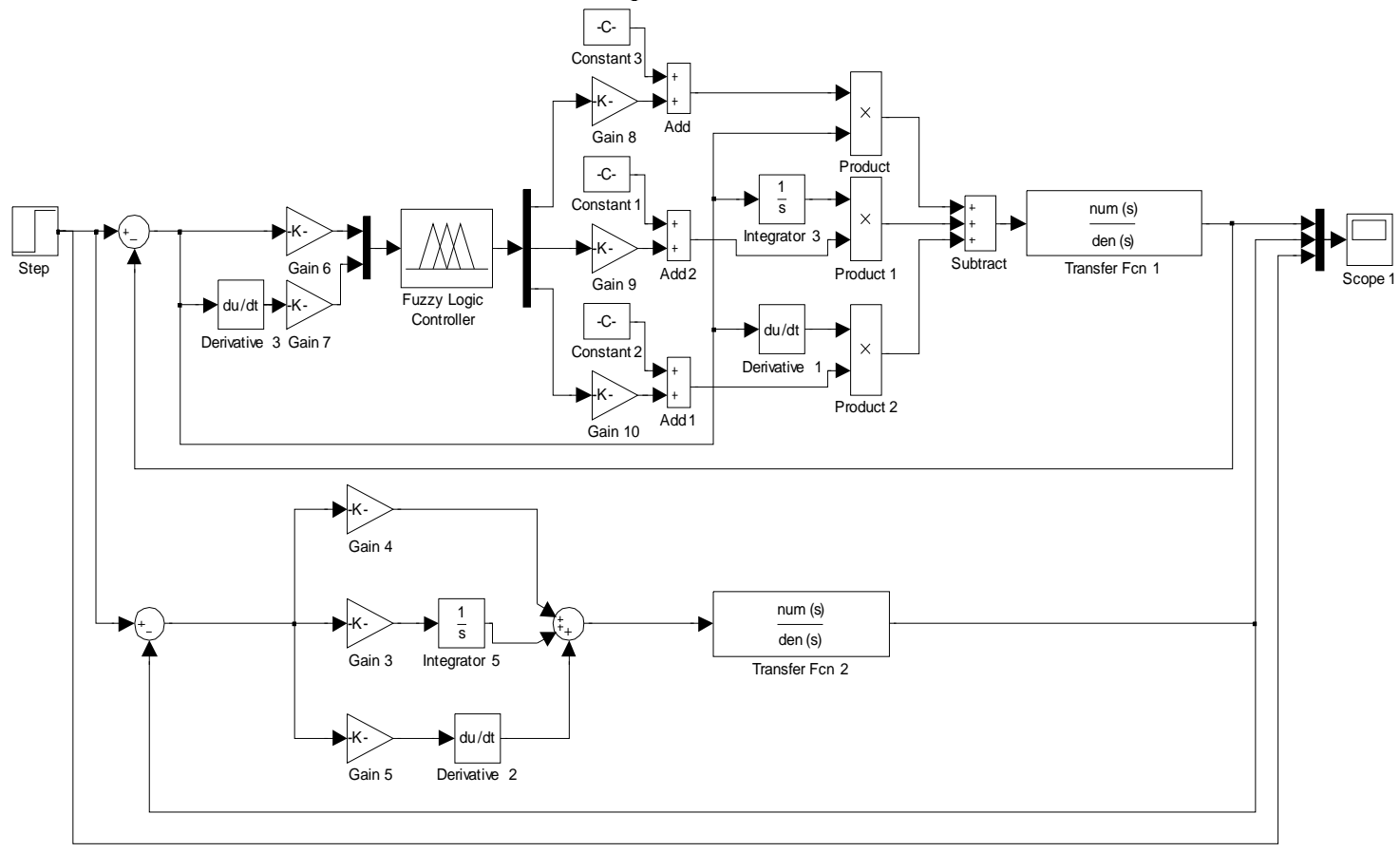

Fig. 10 Simulation Model of System Simulink

The adjusting curves of the self-tuning PID controller parameters $\Delta K_{p}, \Delta K_{i}, \Delta K_{d}$ are shown in figure 11-13. 


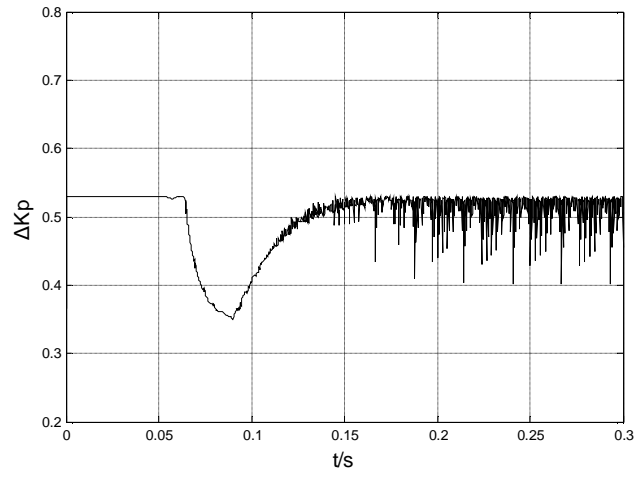

Fig.11 Adaptive Adjustment of $\Delta K_{p}$

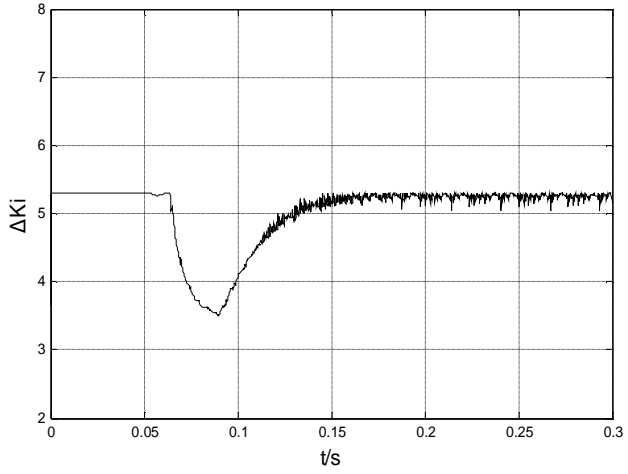

Fig.12 Adaptive Adjustment of $\Delta K$

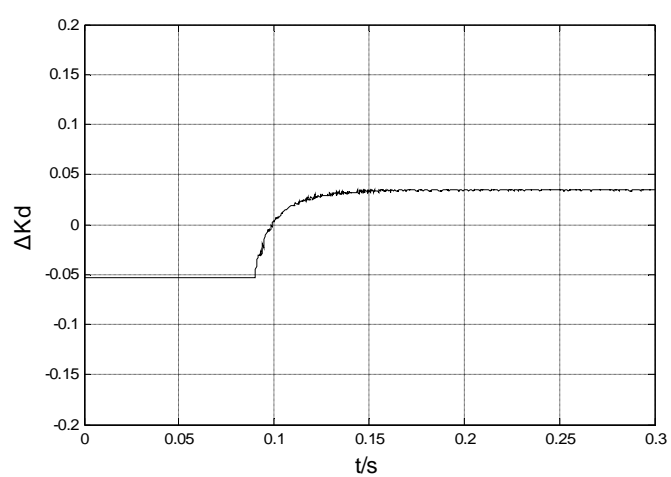

Fig.13 Adaptive Adjustment of $\Delta \mathrm{K}_{\mathrm{d}}$

Emulate the compared method between the output results of simple PID control and the output results of fuzzy self-tuning PID controller. The simulation results are shown in figure 14.

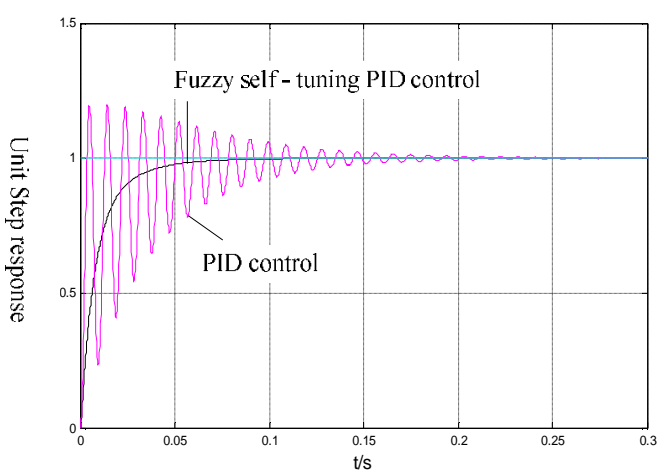

Fig. 14 Comparison of Unit Step Response

It can be seen from the figure 14 that compared with the traditional PID controller, the step response time of the system is shortened by about $50 \%$ by using the fuzzy self-tuning PID controller, with non-overshoot and small steady-state error.

\section{Result analysis}

Using the force sensing system of master-slave manipulator as the application background, and aiming at the existing problems about about large disturbances, delays and nonlinear in the system, we propose a design method of fuzzy self-tuning PID controller, and get the following conclusions through the simulation analysis.

(1) Compared with the traditional PID controller, the fuzzy self-tuning PID controller can shorten the step response time of the system by about $50 \%$, with non-overshoot and small steady-state error. 
(2) Compared with the traditional PID controller, the parameters fuzzy self-tuning PID controller has better robustness, and it can overcome the effect of large disturbance, nonlinear and other factors on the control accuracy, which makes the system maintain fast response speed and higher control accuracy.

\section{References}

[1] Chen Zhongkai. Research on master-slave manipulator clamping force servo system control [D]. University of Science and Technology of China, 2015.

[2] Huang Xiaoyu. Computer simulation of fuzzy self-tuning PID parameter controller based on MATLAB[J]. Automation and Instrumentation, 2001, 3:21-24.

[3] Gao Hongwei, Zhao Baoyong, Fu Xingwu.MATLAB simulation research of fuzzy self-tuning PID control strategy[J]. Electrical Drive Automation, 2002,24 (5): 21-24.

[4] Li Ping, Li Feng, Zhao Hu et al. Design and simulation of fuzzy self-tuning PID controller[J]. Journal of Instrumentation, 2004,25 (4): 264-267.

[5] Chen Jing, Pei Xiping, Shi Xiaoying, et al.Design and simulation of a fuzzy self-tuning PID controller[J]. Journal of Hubei Institute of Engineering, 2003, 18 (6): 30-32.

[6] Cheng Qijian. Research and application on fuzzy self-tuning PID controller[D]. Xi'an University of Technology, 2016.

[7] Wu Bin. Design and development of fuzzy self-tuning PID controller[D]. North China Electric Power University, 2015.

[8]Kwok D P,Tam P,Li C K,et al.Analysis and design of fuzzy PID control systems[C]. IEEE international Conference on Control, 1991, Vol. 2, pp: 955-960. 


\title{
Studies on Spray Characteristics of Kerosene Alternative Fuels for Special Vehicle Diesel Engines
}

\author{
Zhixin Sun ${ }^{1, a}$, Xinyong Qiao ${ }^{1, b}$, Ruoting $\mathrm{Li}^{1, \mathrm{c}}$ and Ning Ma ${ }^{1, \mathrm{~d}}$ \\ ${ }^{1}$ Department of Mechanical Engineering, Academy of Armored Force Engineering, \\ Beijing, China, 100072 \\ Corresponding author: ${ }^{\mathrm{a}}$ sunzhi-li@163.com, ${ }^{\mathrm{b}} \mathrm{qxyaafe@sina.com},{ }^{\mathrm{c} l i r u o t i n g 1987 @ 126 . c o m}$, \\ dm18610465261@163.com
}

Keywords: special vehicle; diesel engine; kerosene; emergency alternative fuels; spray Abstract. Experimental studies to compare spray characteristics of kerosene fuels and diesel fuel were performed in a constant-volume vessel. Three kinds of fuels such as -10\# diesel, aviation kerosene and lamp kerosene were tested. The spray characteristics were studied by use of the shadowgraph method. The spray cone angle and penetration were observed. In general, the spray cone angles of the kerosene fuels are slightly larger than that of diesel fuel. In the initial range of the spray, about $0 \sim 0.5 \mathrm{~ms}$, the spray cone angles of aviation kerosene and lamp kerosene are bigger than diesel fuel at the same time, by $11.2 \%$ and $10.3 \%$. The spray penetration of the two kerosene fuels are nearly the same with the difference less than 3\%. Meanwhile the penetration of diesel fuel is significantly about $18.3 \%$ and $17.1 \%$ longer than kerosene fuels.

\section{Introduction}

Special vehicles are used to carry out so many important works, such as military actions, engineering rescues and fire-fighting rescues. Considering the particularities of their working circumstances, they wouldn't accomplish their tasks for fuel shortage if their fuel supply chain, which consists of the fuel depots, fuel supply stations and pipelines is cut off. Therefore, how could we solve the fuel supply problem while the special vehicles have urgent tasks to accomplish fuel the special vehicle engines with alternative fuel that could be found easily without engine structure modification is a realistic measure. Kerosene is one of the best options.

Kerosene a middle distillate of petroleum based fuel. Generally, it can be classified as two types by purpose of use: aviation kerosene and lamp kerosene. From 1990s, many abroad researchers have carried out studies on the performances and emissions on engines fueled with kerosene [1-5]. But no reports was retrieved about the special vehicle engines fueled with kerosene at home.

In the working process of diesel engine fueled with alternative fuels, the changes of fuel physical and chemical properties lead to the changes of fuel spraying characteristics, and directly affect the combustion efficiency, power output and economy of diesel engine [6]. Therefore, experimental studies on the kerosene fuel spray characteristics in constant volume vessel were carried on in this paper. The results provide the experimental basis for the application of kerosene as special vehicles alternative fuels when emergency.

\section{Test Equipment and Scheme}

Test Equipment. This fuel spraying test was carried out on a constant volume vessel bench which is designed to study fuel spraying. The test system is composed of a constant volume vessel, a common rail system, a high-speed photography system, a data acquisition system and a control system, as shown in figure 1. 


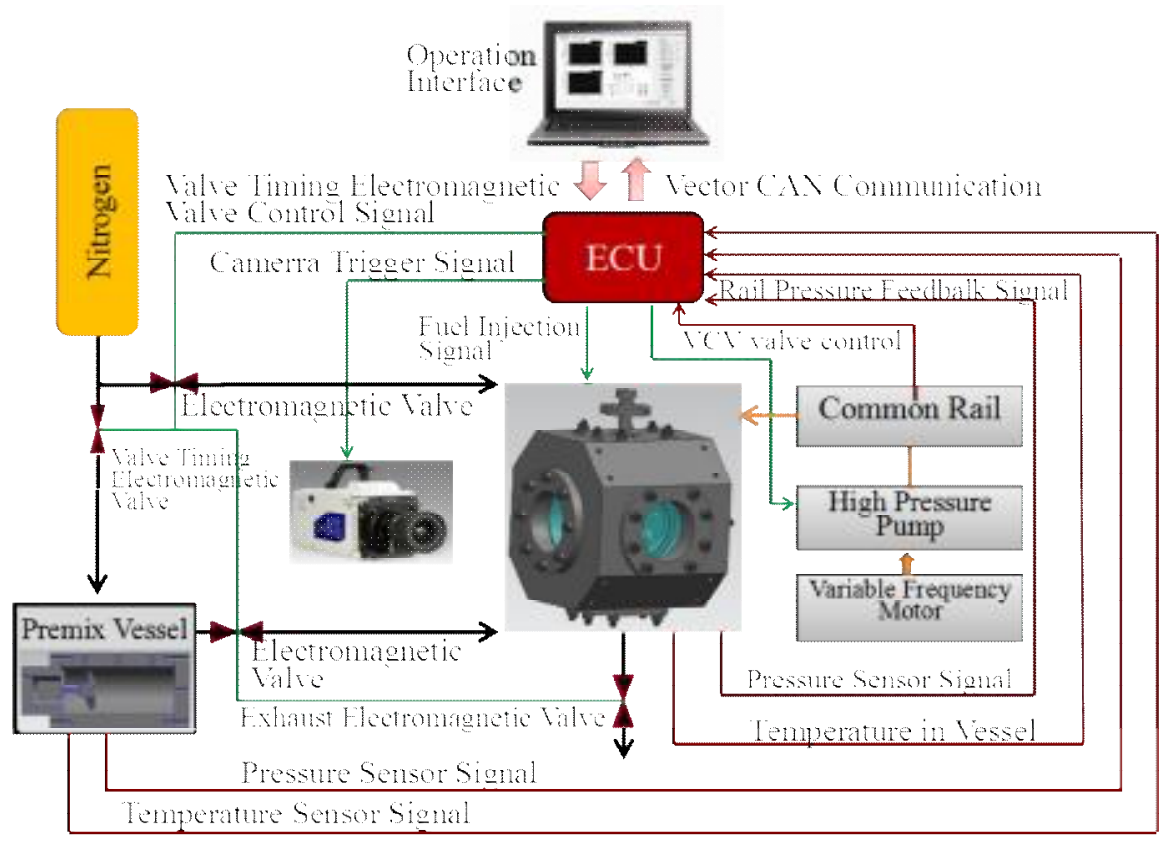

Figure 1 Test system for fuel spray

Tested Fuels. Three kinds of fuels were tested: $-10^{\#}$ diesel, aviation kerosene and lamp kerosene. The main physical and chemical properties are shown in Table 1.

Table 1 Physical and chemical properties of the tested fuels

\begin{tabular}{|l|l|l|l|}
\hline Item & Diesel & $\begin{array}{l}\text { Aviation } \\
\text { kerosene }\end{array}$ & $\begin{array}{l}\text { Lamp } \\
\text { kerosene }\end{array}$ \\
\hline Density $\left(20^{\circ} \mathrm{C}\right) /\left(\mathrm{g} \cdot \mathrm{cm}^{-3}\right)$ & 834.0 & 785.4 & 794.0 \\
\hline Viscosity $\left(20^{\circ} \mathrm{C}\right) /(\mathrm{mm} 2 \cdot \mathrm{s}-1)$ & 4.611 & 1.506 & 1.826 \\
\hline Flash point $/{ }^{\circ} \mathrm{C}$ & 79.5 & 53.5 & 50.5 \\
\hline $10 \%$ recovery temperature $/{ }^{\circ} \mathrm{C}$ & 231.0 & 171.0 & 181.4 \\
\hline $50 \%$ recovery temperature $/{ }^{\circ} \mathrm{C}$ & 270.5 & 188.0 & 205.9 \\
\hline $90 \%$ recovery temperature $/{ }^{\circ} \mathrm{C}$ & 320.0 & 214.5 & 236.0 \\
\hline Cetane number & 50.8 & 53.5 & 49.1 \\
\hline Lower heat value $/(\mathrm{MJ} \cdot \mathrm{kg}-1)$ & 43.18 & 42.90 & 41.00 \\
\hline
\end{tabular}

As shown in table 1: compared with diesel fuel, aviation kerosene or lamp kerosene has significantly lower viscosity and density, better fluidity. But their flash point and distillation temperature are lower, which leads to worse safety. The cetane number of aviation kerosene is higher than that of diesel oil, while lamp kerosene is slightly lower. And the Lower Calorific Value of these two kinds of kerosene fuel are lower than that of diesel fuel.

Test scheme. The spray characteristics of three kinds of fuels were studied by means of the shadowgraph. The whole spray process was recorded. A single hole injector was used, and diameter of the hole is $0.28 \mathrm{~mm}$. Each test was repeated 3 times in order to reduce the error. The test condition is shown in Table 2 .

Table 2 Test condition of fuel spray

\begin{tabular}{|c|c|}
\hline Environment temperature/K & 298 \\
\hline Injection pressure/MPa & 30 \\
\hline Injection pulse width/ms & 3 \\
\hline Background pressure/MPa & 1.0 \\
\hline $\begin{array}{c}\text { High speed camera photographic } \\
\text { speed/ ( frame } \text { s }^{-1} \text { ) }\end{array}$ & 50000 \\
\hline Resolution/pixel & $178 \times 446$ \\
\hline Exposure time/ $\mu \mathrm{s}$ & 1.1 \\
\hline
\end{tabular}




\section{Test Results and Analysis}

Analysis of Spray Characteristics. Figure 2 shows the development of diesel and kerosene fuels' spray, from the beginning of injection to $1.68 \mathrm{~ms}$ after injection.

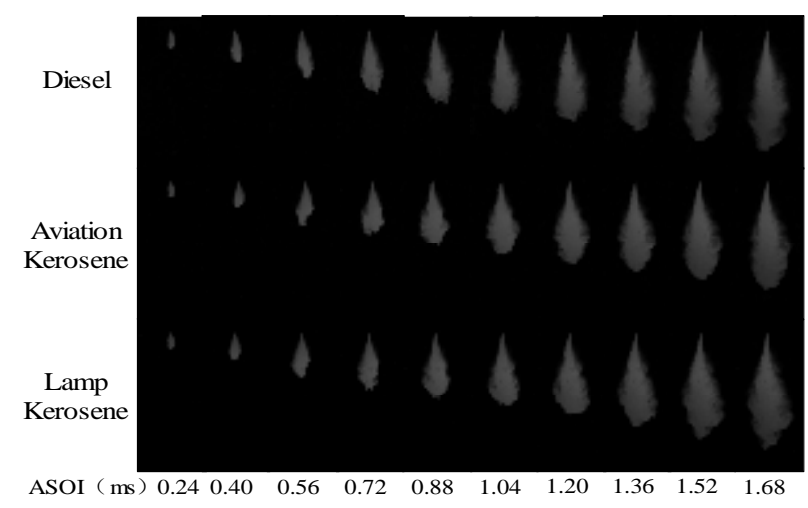

Figure 2 Spray shapes of different fuels

It is shown that the spray shapes of the three kinds of fuel have the same regularity in the developing process: the spray appeared an umbrella shape; With the development of the spray, air in the chamber is entrained into the interior of the fuel spray, mixed with the broken fuel droplets; Compared with the kerosene fuel, the spray of the diesel fuel is narrower in the front part; its spray develops faster and impinged the wall of the cylinder earlier.

Figure 3 shows the variations of different fuels' spray cone angle developed with time. In general, the spray cone angles of the two kinds of kerosene fuels are slightly larger than that of diesel fuel. In the initial range of the spray, about $0 \sim 0.5 \mathrm{~ms}$, the spray cone angles of aviation kerosene and lamp kerosene are $11.2 \%$ and $10.3 \%$ more than that of diesel fuel at the same time. As time passed, the spray cone angle of the lamp kerosene is nearly the same as that of the diesel fuel. The difference is less than $2 \%$. And the spray cone angle of aviation kerosene is $4.8 \%$ bigger than that of diesel fuel.

Figure 4 shows the variations of different fuels' spray penetration with time. It can be seen that the spray penetration curves of the two kerosene fuels are nearly same. The difference is less than $3 \%$. Meanwhile the spray penetration of diesel is significantly longer. Compared with aviation kerosene and lamp kerosene, the differences are about up to18.3\% and $17.1 \%$.

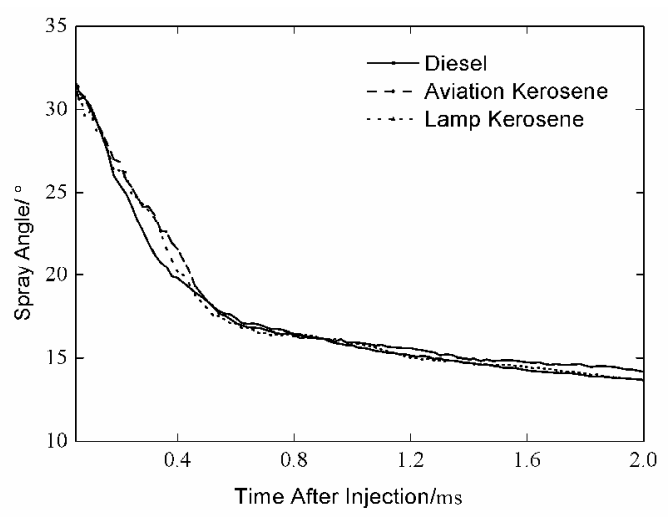

Figure 3 Comparison of spray cone angle of different fuels 


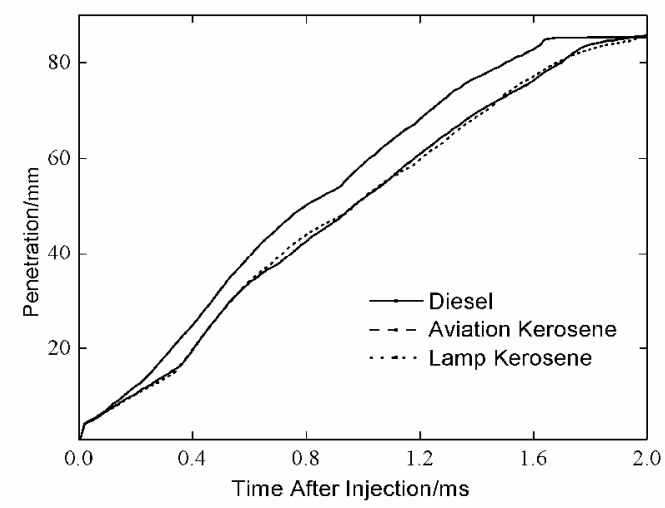

Figure 4 Comparison of spray penetration of different fuels

This is due to the fact that under the same injection pressure and background pressure the spray cone angles and penetration distances are closely related to the physical properties of the fuel. For kerosene fuel, its viscosity and density are relative less than those of diesel fuel, so the quality and momentum are smaller. During the crushing process the viscous force and inertia force of the fuel spray are smaller too. The droplets are more easily broken. This leads to larger spray cone angle and shorter penetration distance. The difference of the two kerosene fuels' physical properties is small, and the spray cone angle and penetration are general the same.

\section{Conclusions}

The viscosity and density of kerosene fuel is lower than that of diesel fuel, and the fuel droplet is easier to break in the spray process, which leads to the increase of spray cone angle and the decrease of the penetration distance.

\section{Acknowledgements}

This work was financially supported by Academy of Armored Force Engineering (2014YY02).

\section{References}

[1] Andrews G E, Abdelhalim D M, Williams P T. Characterization of diesel particulate emission of two IDI diesel engines using diesel and kerosene fuels SAE Paper 961231, (1996).

[2] Bergstrand P. Effects on combustion by using kerosene or MK1 diesel. SAE Paper 2007-01-0002, (2007).

[3] Cracknell R F, Rickeard D J. Advanced combustion for low emissions and high efficiency part 2: impact of fuel properties on HCCI combustion. SAE Paper 2008-01-2404, (2008).

[4] Rose K D, Cracknell R F, Rickeard D J, et al. Impact of fuel properties on advanced combustion performance in a diesel bench engine and demonstrator vehicle. SAE Paper 2010-01-0334, (2010).

[5] Pischinger S, Rajamani V K, Jeihouni Y. Impact of fuel properties on the performance of a direct injection diesel engine under part homogeneous operating conditions. SAE Paper 2011-01-1358, (2011).

[6] Emekwuru N. Numerical characterization of two alternative-to-diesel fuels using a moments spray model.SAE Paper 2014-01-1422, (2014). 


\title{
Adsorption of atrazine from aqueous solution using magnetic grapheme oxide
}

\author{
Xiaojun Zhang, Xiaoguo Ma*, Weiheng Shu and Junbiao Peng \\ School of Environmental Science and Engineering, Guangdong University of Technology, \\ Guangzhou 510006, China \\ xgma@21cn.com
}

Keywords: Magnetic graphene oxide; atrazine; adsorption.

Abstract. Magnetic graphene oxide (MGO) was prepared, and characterized using Fourier transform infrared spectroscopy and transmission electronic microscopy. The MGO was used as the sorbent for adsorption of atrazine, and the adsorption performance was investigated under various conditions. Results indicated that the adsorption equilibrium was achieved within $2 \mathrm{~h}$, the adsorption capacity was $7.52 \mathrm{mg} / \mathrm{g}$, and the adsorption process could be well described by Freundlich isotherm model and pseudo-second-order kinetic model. The hexatomic ring as well as carboxyl, carbonyl, epoxy and hydroxy groups on MGO were the main adsorption sites, and there are $\pi-\pi$ interaction and hydrogen -bond interaction of MGO with atrazine. The experimental results showed MGO could be a potential adsorbent for removal of atrazine from aqueous solution.

\section{Introduction}

Atrazine (2-chloro-4-ethylamino-6-isopropylamino-1, 3, 5-triazine) is the most widely used herbicide, which is mainly used to remove broadleaf and grassy weeds in corn or crops. Atrazine is now considered as a potential contamination which can cause cancer and do harm to endocrine system of human [1]. Nowadays, atrazine has been detected in various environmental matrices. Consequently, it is necessary to remove atrazine from wastewater. Adsorption is one of the most important methods for separation of metal ion and organic pollutants from aqueous solutions [2-4], due to its high efficiency and easy operation. Obviously, sorbent is the key factor of this technique.

Graphene oxide (GO) is the oxidized derivative of graphene, which possesses an ultrahigh-specific surface area, superior chemical property and excellent thermal stability. Therefore, GO has great promise for use as adsorbent materials [5].

Magnetically separation technology provides an easy and rapid way for removal of magnetic particles from solution by applying an appropriate magnetic field [6]. Thus, magnetic adsorbent can be easily isolated from matrix solutions after adsorption of target compounds.

In this work, magnetic (MGO) was prepared and characterized, and was applied for the removal of atrazine from aqueous solution. The adsorption behaviors of atrazine on the MGO were investigated and evaluated.

\section{Materials and methods}

\section{Reagents}

Atrazine was obtained from Aladdin Reagent (Shanghai) Co., Ltd (Shanghai, China).Nature graphite powder $(99.95 \%)$ was purchased from Sinopharm Chemical Reagent Co., Ltd (Shanghai, China). Other chemicals and materials were purchased from Tianjin Damao Chemical Reagent Factory (Tianjin, China).

Instruments

A 7890A-5975C GC-MS system (Agilent, USA) using a HP-5MS capillary columnwas utilized for separation and analysis. 


\section{Preparation of $M G O$}

Graphite oxide (GO) was prepared from nature graphite powders by a modified Hummers method [7]. Magnetic graphite oxide (MGO) was synthesized by a one-pot solvothermal reaction [8].

\section{Results and discussion}

\section{Characterization of $M G O$}

The FT-IR spectrum of the prepared MGO is shown in Fig.1. As can be seen, the peak at $571 \mathrm{~cm}^{-1}$ was related to $\mathrm{Fe}-\mathrm{O}$ stretching vibrations. The peak at $1398 \mathrm{~cm}^{-1}$ was assigned to $\mathrm{C}=\mathrm{C}$ from unoxidized $\mathrm{sp}^{2} \mathrm{CC}$ bonds. The peak at $1576 \mathrm{~cm}^{-1}$ corresponded to $v(\mathrm{C}=\mathrm{O})$ of $-\mathrm{COOH}$ on the $\mathrm{GO}$ after coating with $\mathrm{Fe}_{3} \mathrm{O}_{4}$. The peaks at $3385 \mathrm{~cm}^{-1}$ was attributed to $\mathrm{O}-\mathrm{H}$ stretching vibrations.

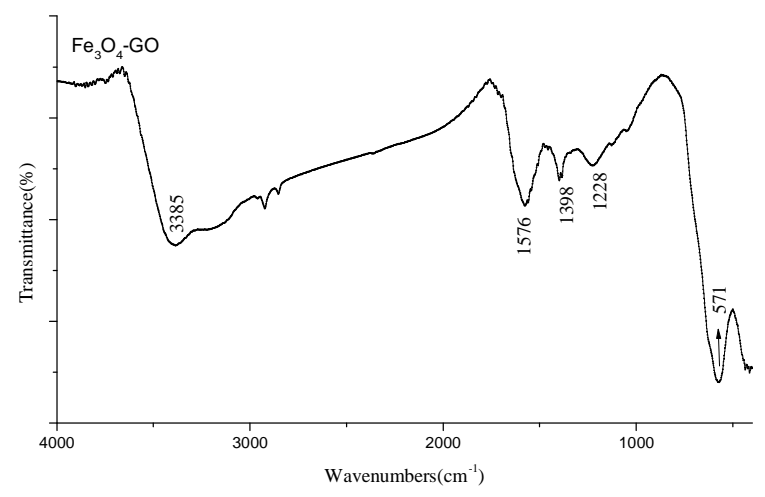

Fig.1 FTIR spectrum of MGO.

From the TEM observation (Fig.2), it was found that the $\mathrm{Fe}_{3} \mathrm{O}_{4}$ particles on $\mathrm{GO}$ were almost regular in shape with an average diameter of around $20 \mathrm{~nm}$.

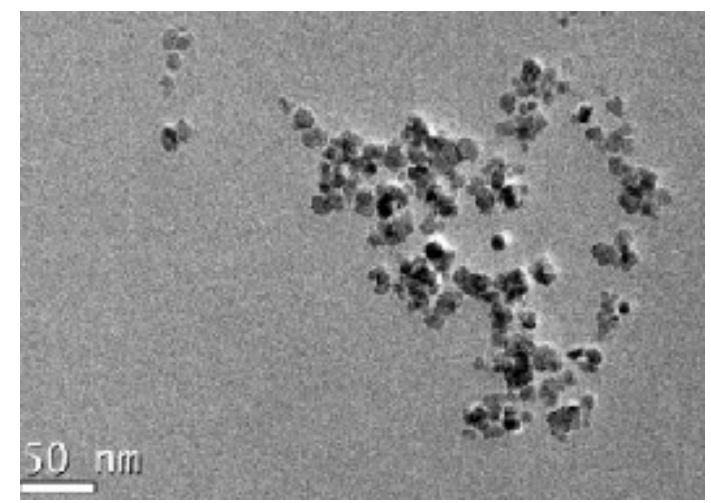

Fig.2 TEM image of MGO.

The magnetic property of the MGO was tested with a vibrating sample magnetometer. The greatest saturation magnetization was $29.8 \mathrm{emu} / \mathrm{g}$, and both the remanence and coercivity were near zero, suggesting that the MGOwere superparamagnetic.

The adsorption of atrazine on the MGO was examined using batch experiments and conducted in duplicate. The adsorption capacities varied with initial atrazine concentrations (Fig.3). Langmuir and Freundlich isotherms were used to describe the adsorption behaviors. Freundlich isotherm mode fitted the experimental data better $\left(R^{2}=0.9987\right)$ than the Langmuir model $\left(R^{2}=0.8703\right)$, suggesting that the adsorption of atrazine onto the MGO followed the Freundlich isotherm (Fig.4). The 
maximum adsorption capacity was $7.5 \mathrm{mg} / \mathrm{g}$ at an initial atrazine concentration of $10 \mathrm{mg} / \mathrm{L}$. Some important thermodynamic parameters variations including standard Gibbs free energy $\left(\triangle G^{0}\right)$, enthalpy $\left(\triangle H^{0}\right)$ and entropy change $\left(\triangle S^{0}\right)$ for the adsorption process were obtained. $\triangle G^{0}$ has negative value $(-12.5 \mathrm{KJ} / \mathrm{mol})$, indicating that the adsorption was spontaneous. On the other hand, the positive value of $\triangle H^{0}(50.9 \mathrm{KJ} / \mathrm{mol})$ suggested an endothermic nature of atrazine adsorption.

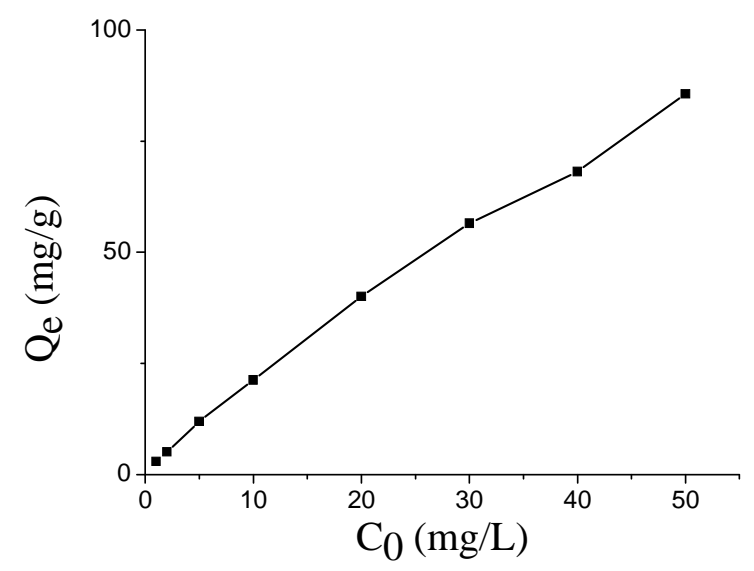

Fig.3 Atrazine adsorption on MGO at different initial concentrations.

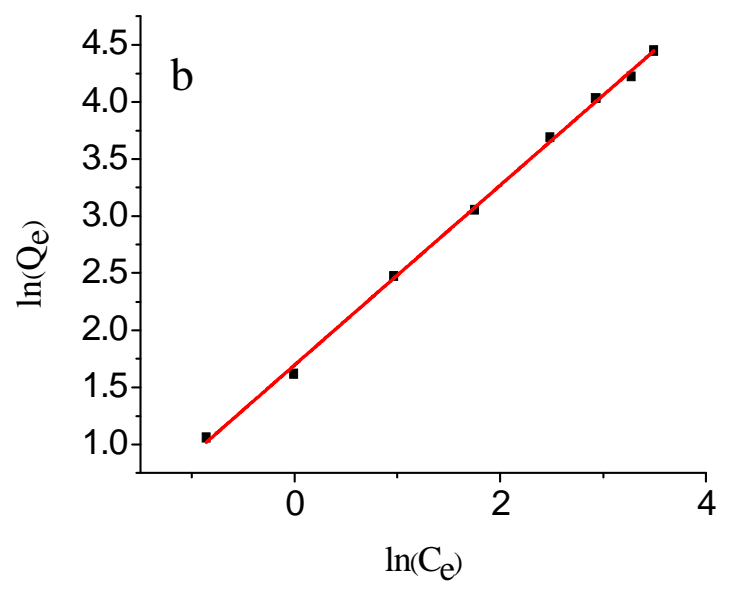

Fig.4 Freundlich isotherm model for atrazine adsorption on MGO.

The effect of contact time on atrazine adsorption with the MGO was investigated using an initial concentration of $50 \mathrm{mg} / \mathrm{L}$. The results (Fig.5) showed that the adsorption occurred rapidly within the first $1 \mathrm{~h}$ and then gradually slowed down until reaching equilibrium $(2 \mathrm{~h})$. The kinetics of atrazine adsorption was studied by using pseudo-first-order and pseudo-second-order kinetic models. It was found that the pseudo-second order kinetic equation could preferably describe the adsorption (Fig.6). 


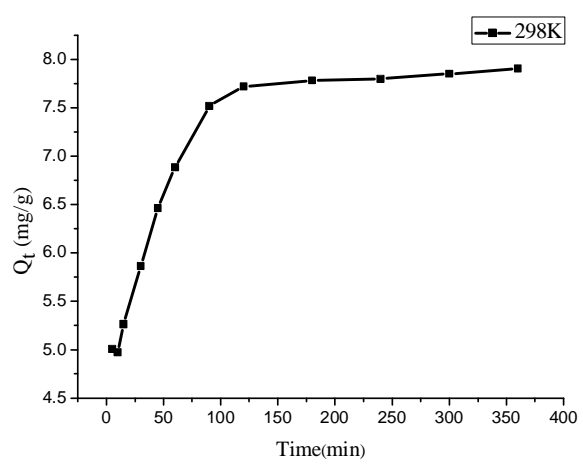

Fig.5 Effect of contact time on atrazine adsorption on MGO.

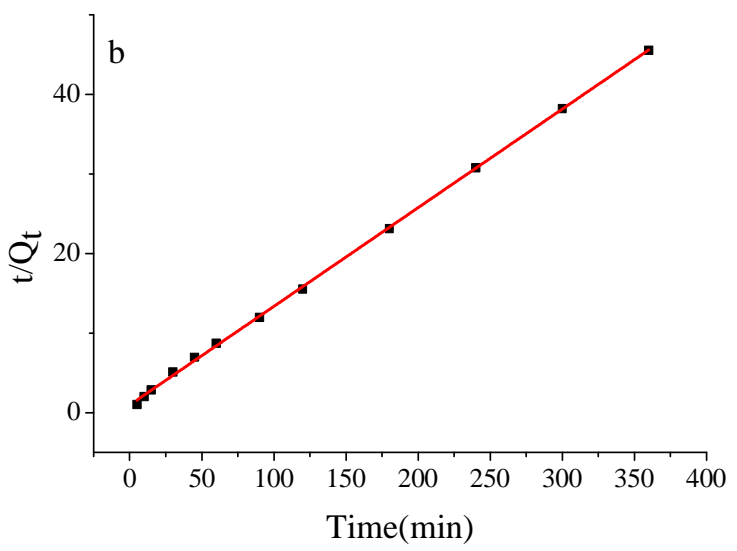

Fig.6 Pseudo-second-order kinetic plots for atrazine adsorption on MGO.

\section{Conclusions}

Magnetic graphene oxide was successfully synthesized and applied to adsorption of atrazine from aqueous solutions. MGO has hexatomic ring as well as carboxyl, carbonyl, epoxy and hydroxy groups, which resulted in $\pi-\pi$ interaction and hydrogen -bond interaction of MGO with atrazine. The adsorption results obtained from this study suggest that the prepared MGO can act as a suitable adsorbent for efficient removal of low concentration of atrazine in industrial effluents.

\section{Acknowledgements}

This work was financially supported by the National Natural Science Foundation of China (No.41272262), the Science and Technology Planning Project of Guangdong Province, China (No. 2014A040401077), and the Major Projects (Natural Science) of Education Department of Guangdong Province, China (No.261555101).

\section{References}

[1] Min G., Wang S. and Zhu H. Sci. Total Environ. 2008, 396(1): 79-85

[2] Zou J., Ma X., Dang Y. and Chen Y. J Anal At Spectrom. 2014; 29(9): 1692-1697.

[3] Chen J., Ma X. and Wu Y. Food Anal Methods. 2014; 7(5): 1083-1089.

[4] Li C., Ma X., Zhang X., et al. J. Sep. Sci., 2017, 40(7): 1621-1628.

[5] Li D., Ma X., Wang R., et al.. Anal. Bioanal. Chem., 2017, 409(5): 1165-1172.

[6] Chen Y., Ma X., Huang M., Peng, J., Li C. Anal Methods. 2016; 8(4): 824-829. 
[7] Marcano, D. C., Kosynkin, D. V., Berlin, J. M., Sinitskii, A., Sun, Z. and Slesarev, A. ACS Nano. 2010, 4, 4806-4814

[8] Chandra, V., Park, J., Chun, Y., Lee, J.W., Hwang, I. C.and Kim, K. S. ACS Nano.2010, 4(7), 3979-3986. 